\title{
Modulation of mechanosensory vibrissal responses in the trigeminocervical complex by stimulation of the greater occipital nerve in a rat model of trigeminal neuropathic pain
}

Nuria García-Magro ${ }^{1,2}$, Pilar Negredo ${ }^{1}$, Yasmina B. Martin ${ }^{3}$, Ángel Nuñez ${ }^{1+}$ and Carlos Avendaño ${ }^{1 * \dagger}$ (D)

\begin{abstract}
Background: Stimulation of the occipital or trigeminal nerves has been successfully used to treat chronic refractory neurovascular headaches such as migraine or cluster headache, and painful neuropathies. Convergence of trigeminal and occipital sensory afferents in the 'trigeminocervical complex' (TCC) from cutaneous, muscular, dural, and visceral sources is a key mechanism for the input-induced central sensitization that may underlie the altered nociception. Both excitatory (glutamatergic) and inhibitory (GABAergic and glycinergic) mechanisms are involved in modulating nociception in the spinal and medullary dorsal horn neurons, but the mechanisms by which nerve stimulation effects occur are unclear. This study was aimed at investigating the acute effects of electrical stimulation of the greater occipital nerve (GON) on the responses of neurons in the TCC to the mechanical stimulation of the vibrissal pad.
\end{abstract}

Methods: Adult male Wistar rats were used. Neuronal recordings were obtained in laminae II-IV in the TCC in control, sham and infraorbital chronic constriction injury (CCl-loN) animals. The GON was isolated and electrically stimulated. Responses to the stimulation of vibrissae by brief air pulses were analyzed before and after GON stimulation. In order to understand the role of the neurotransmitters involved, specific receptor blockers of NMDA (AP-5), GABA (bicuculline, Bic) and Glycine (strychnine, Str) were applied locally.

Results: GON stimulation produced a facilitation of the response to light facial mechanical stimuli in controls, and an inhibition in CCI-loN cases. AP-5 reduced responses to GON and vibrissal stimulation and blocked the facilitation of GON on vibrissal responses found in controls. The application of Bic or Str significantly reduced the facilitatory effect of GON stimulation on the response to vibrissal stimulation in controls. However, the opposite effect was found when GABAergic or Glycinergic transmission was prevented in CCl-loN cases.

(Continued on next page)

\footnotetext{
*Correspondence: carlos.avendano@uam.es

${ }^{\dagger}$ Ángel Nuñez and Carlos Avendaño contributed equally to this work.

'Department of Anatomy, Histology and Neuroscience, Medical School, Autonoma University of Madrid, c/ Arzobispo Morcillo 2, 28029 Madrid, Spain Full list of author information is available at the end of the article
}

(c) The Author(s). 2020 Open Access This article is licensed under a Creative Commons Attribution 4.0 International License, which permits use, sharing, adaptation, distribution and reproduction in any medium or format, as long as you give appropriate credit to the original author(s) and the source, provide a link to the Creative Commons licence, and indicate if changes were made. The images or other third party material in this article are included in the article's Creative Commons licence, unless indicated otherwise in a credit line to the material. If material is not included in the article's Creative Commons licence and your intended use is not permitted by statutory regulation or exceeds the permitted use, you will need to obtain permission directly from the copyright holder. To view a copy of this licence, visit http://creativecommons.org/licenses/by/4.0/. The Creative Commons Public Domain Dedication waiver (http://creativecommons.org/publicdomain/zero/1.0/) applies to the data made available in this article, unless otherwise stated in a credit line to the data. 


\begin{abstract}
(Continued from previous page)
Conclusions: GON stimulation modulates the responses of TCC neurons to light mechanical input from the face in opposite directions in controls and under CCI-loN. This modulation is mediated by GABAergic and Glycinergic mechanisms. These results will help to elucidate the neural mechanisms underlying the effectiveness of nerve stimulation in controlling painful craniofacial disorders, and may be instrumental in identifying new therapeutic targets for their prevention and treatment.
\end{abstract}

Keywords: GABA, Glycine, Allodynia, NMDA, Neuromodulation

\section{Introduction}

The electrical stimulation of peripheral nerves has become a growing trend during the last decade to treat many drugresistant painful conditions (recent reviews in [1-3]). Chronic refractory headaches are favored targets for neuromodulation, in particular neurovascular or autonomicrelated cephalalgias, such as chronic migraine, cluster headache or hemicrania continua [4-8], and painful neuropathies originating in a trigeminal branch or occipital nerve [9-11]. The stimulation of the greater occipital nerve (GON) has proved successful for medically intractable chronic migraine and neurovascular headaches [12-15], and a few studies have reported promising results in treating refractory trigeminal neuralgia [16].

The mechanisms by which GON stimulation relieves pain from disparate craniofacial territories are still obscure. It is generally assumed that nociceptive inputinduced sensitization occurs in second-order neurons on which primary afferents from such territories converge $[17,18]$, a process that could underlie the development of migraine and trigeminal autonomic cephalalgias [19-21]. Lack of habituation and/or sensitization of central trigeminal neurons have been shown to occur in a variety of primary headaches, both during ictal and interictal periods, and these dysfunctions are a target for the clinical assessment of patients as well as the exploration of novel therapeutic strategies [22-25]. The central node for neural convergence would be the 'trigeminocervical complex' (TCC), identified as an area in the upper cervical and medullary dorsal horn where primary afferents from various cutaneous, muscular, dural, and visceral trigeminal and occipital sources distribute $[19,26,27]$. It was first shown in rats that the neurons in the caudal part of the TCC displayed crossed sensitization and functional coupling to input from nociceptive supratentorial dural afferents, which course along the trigeminal nerve, and cervical afferents conveyed through the GON $[19,28]$. However, in a rat model of migraine GON electrostimulation induced lasting elevations of mechanical allodynia thresholds at trigeminal and other bodily regions [29], and reduced tonic and burst firing of ventroposteromedial thalamic neurons in response to mechanosensory stimuli [30].

In an attempt to clarify these apparently conflicting results, Lyubashina et al. [31] studied the effect of GON preconditioning using different stimulation parameters on eleven TCC neurons that showed convergence of GON, supratentorial dura and facial cutaneous inputs, and found consistent reductions in the spontaneous activity and responsivity to receptive field stimulation. These authors suggested that convergence on widedynamic range (WDR) neurons in TCC could result in facilitation or inhibition, depending on the stimulation parameters and the nociceptive state of the subject. In fact, both excitatory glutamatergic and inhibitory GABAergic mechanisms have been involved in the modulation of nociception in TCC neurons. The NMDA receptor blockade reduced the increase in c-Fos expression in superficial laminae of TCC induced by electrical or chemical stimulation of the dural sinuses or the occipital muscles [32, 33], and inhibited nociceptive perivascular dural stimuli-induced firing in laminae I-IV neurons of spinal segments $C_{1}-C_{2}[34,35]$. Moreover, following the demonstration that GABA modulates nociceptive input in the TCC through $\mathrm{GABA}_{\mathrm{A}}$ receptors [36], it was shown that pain-generating peripheral nerve injuries resulted in GABA molecular markers and GABA-mediated inhibition in the dorsal horn being reduced, both in spinal cord slices $[37,38]$, and in the caudal division of the spinal trigeminal nucleus (Sp5C) in anesthetized rats [39].

In this study we aimed at investigating the acute effects of the electrical stimulation of the greater occipital nerve $(\mathrm{GON})$ on the responses of neurons in the TCC to the mechanical stimulation of the vibrissal pad in control rats and rats that display allodynia following constriction injury of a trigeminal nerve branch. Our results found modulating and opposite effects of GON stimulation in each group and shed light on the involvement in these effects of NMDA-dependent excitatory and GABAergic and Glycinergic inhibitory mechanisms.

\section{Materials and methods}

\section{Animals and loN surgery}

Forty-three 3-month-old male Wistar rats (RccHan:Wis, ENVIGO, The Netherlands) were used in this study. All procedures followed the regulations issued by the Ethical Committee of the Autonoma University of Madrid and the European Community's Council Directive 2010/63/ 
UE. All efforts were made to reduce the number of animals used and their suffering.

Chronic infraorbital nerve constriction (CCI-IoN) was performed on the right side of the animal to induce trigeminal neuralgia [40]. Animals were anesthetized by intramuscular injection of Ketamine (Ketolar, $55 \mathrm{mg} / \mathrm{kg}$ ), Xylazine (Rompun, $15 \mathrm{mg} / \mathrm{kg}$ ) and Atropine $(0.2 \mathrm{~g} / \mathrm{kg}$ ). The IoN was exposed under the vibrissal pad and a single polypropylene monofilament (Surgipro 6.0) ligature was loosely tied around the distal part of the nerve. This procedure altered little, if at all, the circulation through the superficial epineural vasculature [41, 42]. Shamoperated control rats underwent the same surgical procedure until exposing the nerve, which was left untouched. The facial wound was closed with interrupted silk sutures. Age-matched control rats were not operated. After recovery from surgery the operated animals' behavior during grooming or eating did not differ from the controls.

\section{Behavioral testing}

The evaluation of mechanical allodynia was performed using a series of calibrated von Frey nylon monofilaments (North Coast Medical, Inc., Morgan Hill, CA, USA). For 2 days before starting the behavioral tests, the animals were habituated for $1 \mathrm{~h}$ daily to the environment (a quiet room with low red lighting) and the experimenter. Daily tests were then performed for three consecutive days before surgery, to establish the baseline response score, and on days 7, 14 and 21 after surgery. Tests consisted of the application of von Frey's filaments to the bending point on different points of the vibrissal pad. Each filament was presented in three series of five times at $10-20 \mathrm{~s}$ intervals. The first series started randomly on the left or right pad. In the first few control and CCI-IoN rats six filaments, between 0.07 and $8.0 \mathrm{~g}$, were presented in a sequential ascending order. Since the responses to the thinner filaments failed to evoke significant responses in either group, only $4.0 \mathrm{~g}$ and $8.0 \mathrm{~g}$ filaments were tried on the remaining animals. A reduction in the number of filaments used also has the advantage of reducing the testing time and possible stress to the animal $[40,43]$. The responses recorded (and value assigned) were: Face withdrawal ( 0.25 points), brisk head shaking (0.5 points), face withdrawal + ipsilateral eye blink (1.0 point), vocalization (1.0 point) and vigorous face scratching (1.5 points). The points were added up for each testing time point and averaged over the two filaments used to give an overall 'response score'.

\section{Electrophysiological recordings and stimulation}

One day after the final behavioral testing session (22 days post-surgery, dps) in cases with CCI-IoN), the animals were anesthetized with urethane $(1.6 \mathrm{~g} / \mathrm{kg}$ i.p.) to perform unit recordings. With the head of the animal positioned in a stereotactic frame (David Kopf Instruments), a midline incision was made in the skin over the occipital and upper cervical levels. The skin was retracted and secured laterally, together with the cervical muscles, to expose the GON and the first two vertebrae. The GON was identified through the thin layers of fascia [27], and $2 \mathrm{~mm}$ of the nerve were gently separated from the muscle and connective tissue. The posterior arch of the atlas was removed and the atlanto-occipital membrane and the underlying dura mater were incised to expose the caudal part of Sp5C and the spinal segment $C_{1}$.

Tungsten microelectrodes ( $2 \mathrm{M} \Omega$, World Precision Instruments) were lowered with a micromanipulator obliquely into the brain stem, to obtain single unit recordings from neurons in laminae II-IV of the right TCC. The vibrissal pad was mechanically stimulated with electronically gated $20 \mathrm{~ms}$ air puffs through a thin (1 mm inner diameter) polyethylene tube placed at 5-7 $\mathrm{mm}$ distance from the skin, and at a constant pressure (3 psi) using a Picospritzer II. The GON was electrically stimulated with $0.2 \mathrm{~ms}$ single pulses delivered by a Cibertec Stimulator (Madrid, Spain) using a monopolar electrode $(150 \mu \mathrm{m}$, blunt cut stainless steel wire) placed on the GON. The current applied ranged between 100 and $400 \mu \mathrm{A}$, ensuring the absence of muscle twitches.

The experimental protocol consisted of a $9 \mathrm{~s}$ period of spontaneous activity, followed by 50 air puffs delivered at $0.3 \mathrm{~Hz}$. After that, $50 \mathrm{GON}$ pulses at $0.3 \mathrm{~Hz}$ were delivered; each was followed $100 \mathrm{~ms}$ later by an air puff on the vibrissal pad. Signals from TCC recordings were filtered $(0.3-3 \mathrm{kHz})$ and fed to a personal computer at 10 $\mathrm{kHz}$ sampling rate with stimuli events for off-line analysis with Spike 2 (Cambridge Electronic Design, Cambridge, UK). In most cases, small electrolytic lesions (1$2 \mu \mathrm{A} \mathrm{DC}$ for $10 \mathrm{~s}$ ) were made with the same electrode at the end of the session to mark the recording site.

\section{Drug application}

The global pharmacological blockade of NMDA, GABA and/or Glycine receptors in the TCC, particularly in its superficial laminae, was attempted by local infusion of specific receptor antagonists. Amino-5-phosphonovaleric acid or (AP-5, a NMDA receptor antagonist, $50 \mu \mathrm{M}$ ), Bicuculline methiodide (Bic, a $\mathrm{GABA}_{\mathrm{A}}$ receptor antagonist, $20 \mathrm{mM}$ ), Strychnine (Str, an antagonist of the Glycine receptor, $100 \mu \mathrm{M}$ ), or a mixture of Str and Bic were mechanically delivered over the TCC through a glass micropipette $(20-30 \mu \mathrm{m}$ tip outer diameter) attached to a $10 \mu \mathrm{l}$ Hamilton syringe. The injected volume was $2 \mu \mathrm{l}$. All drugs (Sigma, St Louis, MO, USA) were dissolved in saline solution $(0.9 \% \mathrm{NaCl})$. Recordings were started immediately after drug application, with the same protocol as before. 


\section{Tracer injections}

In two control rats, the right trigeminal ganglion (TG) was injected with a transganglionic tracer to appraise the area of overlap of primary afferents from the trigeminal nerve and the GON. Data for the latter were recovered from material used in a prior study from our group (García-Magro et al., 2018). Briefly, the rats were anesthetized with an i.m. injection of Ketamine (Ketolar, 55 $\mathrm{mg} / \mathrm{kg}$ ), Xylazine (Rompun, $15 \mathrm{mg} / \mathrm{kg}$ ) and Atropine $(0.2 \mathrm{~g} / \mathrm{kg})$. The TG was directly accessed through a lateral craniotomy and gentle displacement of the ventral part of the hemisphere. Using a glass micropipette (Systems, Inc) coupled to a $10 \mu \mathrm{l}$ Hamilton syringe, $2 \mu \mathrm{l}$ of a $10 \%$ biotinylated dextran amine (BDA 3000 InvitrogenMolecular, Eugene, OR, USA) solution in saline were slowly injected into Meckel's cavum. Other animals received an intraneural deposit of a mixture of $1 \%$ cholera toxin B (CTB, Sigma-Aldrich) with 2\% isolectin IB4 from Griffonia simplicifolia (Vector Laboratories) into the right GON. Postinjection survival times were 10 and 4 days for rats injected in TG and GON, respectively. The animals were then deeply anesthetized (Dolethal, $50 \mathrm{mg}$ / kg i.p.) and perfused through the ascending aorta with 4\% paraformaldehyde (PFA) in $0.1 \mathrm{M}$ phosphate buffer $(\mathrm{PB})$. The upper cervical spinal cord and caudal twothirds of the brain stem were extracted, postfixed in the same fixative overnight at $4{ }^{\circ} \mathrm{C}$ and cryoprotected with a $30 \%$ sucrose solution in $0.1 \mathrm{M}$ PB for 2 days.

\section{Tissue processing and staining}

The blocks selected for immunohistochemistry were frozen and cut at $40 \mu \mathrm{m}$ in the horizontal plane using a sliding microtome (Leica SM2400, Leica Biosystems, Nussloch). All sections were processed free-floating. Series of sections from TG-injected cases were incubated in avidin-biotin peroxidase (Kit $\mathrm{ABC}$ Elite, 1:250 in PBS; Vector Laboratories, Burlingame, CA, USA) and revealed with diaminobenzidine (DAB, $0.05 \%$ in PBS; Sigma, St. Louis, MO, USA) adding $0.001 \% \mathrm{H}_{2} \mathrm{O}_{2}$. Series from $\mathrm{GON}$-injected rats were first incubated in rabbit anti-CTB (1:500; Sigma Aldrich) or goat anti-IB4 (1: 1000; Vector Laboratories) followed by biotinylated goat anti-rabbit (1:500; Sigma Aldrich) or rabbit anti-goat (1: 250; Vector Laboratories), and then treated in the same way. All sections were mounted on glass slides, dehydrated, defatted and coverslipped with DePeX.

Blocks containing the recording regions were frozen and cut at $40 \mu \mathrm{m}$ in the coronal plane. Sections were Nissl-stained $(0.25 \%$ cresyl violet) to visualize electrode tracks and electrolytic lesion marks.

Material prepared for a previous study [44] was recovered to identify the GABA and Glycine immunoreactive cells in the TCC. Briefly, small blocks containing the medullary dorsal horn were trimmed from resin- embedded slices and serially sectioned at $1 \mu \mathrm{m}$ using an ultramicrotome. Pairs of adjacent sections were collected, and mounted on separate glass slides, which were etched, osmicated and incubated in a wet chamber with either monoclonal anti-GABA antibody (1:250; clone 3D5, [45]), or polyclonal anti-glycine antiserum raised in rabbit (1:1000; Ab139, Chemicon Europe, Hampshire, UK). Appropriate biotinylated secondary antibodies were then used, followed by incubation in $\mathrm{ABC}$ and $\mathrm{DAB}$ as above.

\section{Data analysis}

Units were accepted for statistical analysis when the fluctuations of the unit amplitude were lower than $10 \%$ over the course of the experiment and were also large enough to be well-isolated from multiunit firing activity. Single-unit activity was discriminated by threshold spike detection using SPIKE 2 software for the offline spike sorting (Cambridge Electronic Design, Cambridge). Peristimulus time histograms (PSTHs; $1 \mathrm{~ms}$ bin) of neural responses were also analyzed using SPIKE 2 software. The response was analyzed during the period of vibrissal stimulation and compared with the following period in which GON stimulation had been paired with vibrissal stimulation (100 ms delay). The spike response was measured from the PSTH as the number of spikes evoked in the $0-50$-ms time window after the stimulus onset, divided by the number of stimuli. Response latency was defined as the time elapsed between stimulus onset and the largest peak in the PSTH.

\section{Statistical analysis}

Descriptive statistics (means and SEM) for the parameters analyzed were obtained from the Excel spreadsheet used to perform calculations (Microsoft Office Professional Plus 2010 for Windows 10). Any differences between variables were compared using two-way parametric (Student's $t$ test) or non-parametric (Wilcoxon) tests, after normality testing (D'Agostino-Pearson), with GraphPad Prism software (v. 8.0 for Windows). For behavioral analysis data, global comparisons between the groups and days post-injury were made by two-way ANOVA with repeated measures and SPSS (v. 15). The level of significance was given by the $P$-value and was represented in Figures as $*(p<0.05), *$ $(p<0.01)$ and $* * *(p<0.001)$.

\section{Results}

\section{Coincidence of GON and TG afferents in the TCC}

CTB-labeled, putatively myelinated, afferents from the GON profusely innervate laminae I and III-V of the lateral dorsal horn of the first 6 cervical spinal segments. Sparser projections extend into neighboring Sp5C. IB4labeled, putatively unmyelinated afferents, distribute 
exclusively in laminae I-II of the lateral dorsal horn of segments $\mathrm{C}_{2-3}$ (Fig. 1; see also [27]). Abundant BDAlabeled primary afferents from the TG densely innervate the trigeminal nuclei, reaching the dorsal horn of the upper half of $\mathrm{C}_{2}$ and, more sparsely, further caudally in the spinal cord (Fig. 1a). Recordings from the TCC were obtained from laminae II (inner part), III, or superficial part of IV in the ventrolateral half of the dorsal horn between the caudal part of $\mathrm{Sp} 5 \mathrm{C}$ and the upper part of $\mathrm{C}_{2}$ (Fig. 1b, c).

\section{$\mathrm{CCI}-\mathrm{IoN}$ induced consistent mechanical allodynia}

The responses to mechanical stimuli were evaluated at 7, 14 and $21 \mathrm{dps}$, and compared with the mean control values during the 3 days prior to surgery. As described previously [39, 40], after CCI-IoN the rats developed hypersensitivity to mechanical stimulation on the side ipsilateral to the lesion. The CCI-IoN animals showed a moderate but significant increase on day $7(p=0.010)$ that reached a maximum on postlesion day $14(p=$ $0.003)$ and persisted until the last testing day $(p=0.001)$ (Fig. 2). This increase in responses was restricted to the vibrissal pad, the main territory innervated by the IoN. Responses on the contralateral side were similar to those in control animals, except for some cases that also developed contralateral allodynia, although this was less pronounced than in the operated side (data not shown).

\section{TCC neurons respond differently to vibrissal and GON stimulation under control or CCl-loN conditions}

Spontaneous and evoked activity was examined in TCC neurons in control animals and in the CCI-IoN animals at $22 \mathrm{dps}$, when allodynia was well established. All neurons displayed an ipsilateral RF restricted to a small caudal part of the vibrissal pad, corresponding to one or two adjacent vibrissae in arcs 1-2 or neighboring straddlers [46]. The TCC neurons did not fire, or displayed a low mean firing rate, under spontaneous conditions in control animals $(0.6 \pm 0.2$ spikes/s, $n=49$ neurons, Fig. 3a). Following CCI-IoN, the spontaneous activity of TCC neurons increased fourfold ( $2.4 \pm 0.9$ spikes/s, $n=$ 27 neurons, $p<0.0005$ unpaired test).

Tactile stimuli deflecting the vibrissae (20 ms duration; Fig. 3b) evoked $2.6 \pm 0.23$ spikes/stimulus $(n=49)$ in control animals (measured between 0 and $50 \mathrm{~ms}$ after the stimulus onset; see Methods) with a mean latency of $8.4 \pm 0.3 \mathrm{~ms}$. This response was a $30 \%$ higher in CCI-IoN animals ( $3.4 \pm 0.4$ spikes/stimulus; $n=27, p=0.0307$ unpaired test; Fig. 3c), without a change in latency with respect to controls $(8.6 \pm 0.2 \mathrm{~ms})$.
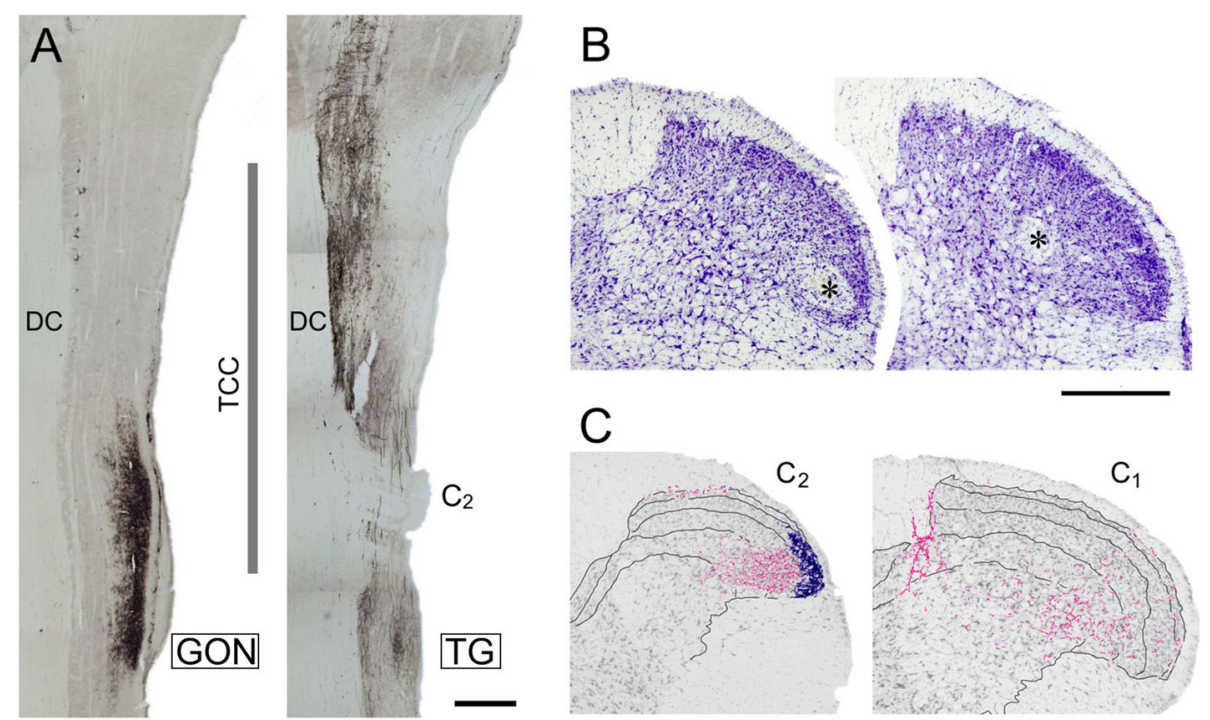

Fig. 1 (a) Coincidence of primary afferents from the GON (left) and the TG (right) in the TCC region. CTB-immunolabeled fibers are shown in two horizontal sections through dorsal levels of spinal and medullary regions that extend from mid-medullary levels (top) to cervical segment $C_{3}$ (bottom). The vertical line marks the approximate rostrocaudal extent of the TCC. In these sections it is clearly seen that afferents from the GON concentrate in TCC at the level of segment C2, while TG afferents extend continuously further caudally. The seeming interruption in TG labeling corresponds to the entry of the dorsal root of spinal nerve $C_{2}$ entering the cord, selected for topographic reference. DC, dorsal column; TCC, trigeminocervical complex. Scale bar $=500 \mu \mathrm{m}$. (b) Two representative examples of small electrolytic lesions (asterisks) through the recording electrode at the end of the recording session. These cases show recording sites in laminae II inner (left) and IV (right) in the ventrolateral one-half of the dorsal horn. Most recordings were placed within the area demarcated by these lesions. (c) The recording sites fell within a territory with substantial innervation of CTB-labeled fibers from the GON (shown in magenta). I-IV laminar boundaries are outlined, and blue stippling indicate IB4-labeled, presumably unmyelinated, afferents in laminae I and II, which were virtually restricted to segments $C_{2}$ and $C_{3}$ (diagram reproduced from Garcia-Magro et al., 2018). Scale bar $=500 \mu \mathrm{m}$ 


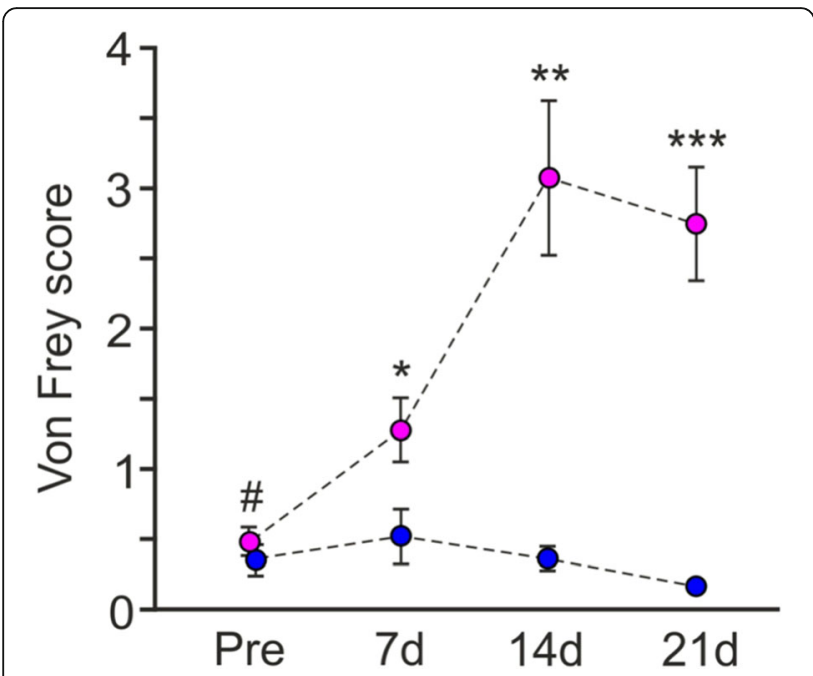

Fig. 2 Testing withdrawal responses to whisker pad mechanical stimulation with von Frey filaments shows a distinct time course over 3 weeks following unilateral (right side) CCI-loN. The response score differed significantly between sham-operated (blue; $n=10$ ) and CCI-loN (magenta; $n=16$ ) groups regarding Group $\left(F_{1,107}=\right.$ 28.906, $p<0.001)$ and Time $\left(F_{3,6}=4.217, p=0.007\right)$, and also showed significant Group $x$ Time interaction $\left(F_{3,107}=5.228, p=0.002\right)$. Data represent means $\pm S E M$, two-way ANOVA with repeated measures, Dunnett T3 post hoc test. Asterisks correspond to $p<0.05\left({ }^{*}\right), p<$ $0.01\left(^{* *}\right)$, and $\left.p<0.001{ }^{* * *}\right)$ for between-group comparisons. Withingroup comparisons showed no changes in control cases, but a significant increase from baseline, pre-CCl values (\#), over the three postsurgery testing days ( $p=0.010,0.003$ and 0.001 for 7,14 , and 21 dps, respectively)

Single electrical stimuli ( $0.2 \mathrm{~ms}$ duration) applied to the GON consistently elicited a response in TCC neurons of $1.8 \pm 0.2$ spikes/stimulus $(n=49)$ in the control animals (measured between 0 and $50 \mathrm{~ms}$ after the stimulus onset) with a mean latency of $3.4 \pm 0.3 \mathrm{~ms}$. In the CCI-IoN animals, their responses to GON stimulation were similar $(1.7 \pm 0.15$ spikes/stimulus; $n=27$ neurons, $p=0.767$ unpaired test; Fig. $3 \mathrm{~d}$ ), as was the response latency $(3.3 \pm 0.3 \mathrm{~ms})$.

\section{GON stimulation modulates vibrissal responses in TCC}

The GON was electrically stimulated (1 pulse; $0.2 \mathrm{~ms}$ ) at different delays before vibrissal stimulation to study its effect on vibrissal responses in the control condition and when allodynia was established in the CCI-IoN animals. The average effect was a facilitation of vibrissal responses in control animals when the delay between the stimuli was shorter than $300 \mathrm{~ms}$. For performing comparisons, we chose a $100 \mathrm{~ms}$ interval (Fig. 4a, b). GON stimulation increased vibrissal responses from $2.6 \pm 0.23$ spikes/stimulus to $3.3 \pm 0.24$ spikes/stimulus when GON and vibrissal stimulation were, paired $(n=61 ; p<0.0001$, paired test; Fig. 4c). This effect was observed in 55 of the 61 TCC cells; in 3 neurons GON stimulation did not modify the response and the response decreased in 3 cells. However, the effect of GON stimulation changed to an inhibition of vibrissal responses when GON and vibrissal stimulation were paired in CCI-IoN animals (from $3.4 \pm 0.4$ spikes/stimulus in control to $2.8 \pm 0.38$ spikes/stimulus with GON stimulation; $n=27 ; p<$ 0.0001 , paired test). This effect was observed in 22 of the 27 TCC cells; in the remaining 5 neurons GON stimulation did not modify the response. The response latency was not modified in any case by the stimulation of the GON (data not shown).

GON-evoked facilitation is dependent of NMDA receptors Vibrissal responses in TCC neurons were reduced when the NMDA-receptor antagonist AP-5 was applied on the TCC area in 10 out of 12 neurons. The response was reduced by $50.2 \pm 10.8 \% 10 \mathrm{~min}$ after AP- 5 application $(n=12 ; p=0.0034$, paired test; Fig. 5). Although previously unreported, we found that AP-5 application also reduced the response of TCC neurons to GON stimulation by $53.5 \pm 12.3 \% 10 \mathrm{~min}$ after AP- 5 application in all the cells tested ( $n=7 ; p=0.0156$, paired test). Accordingly, the GON-evoked facilitation of vibrissal responses observed in the control animals was blocked after AP-5 application (by $30.7 \pm 6.5 \% ; n=12 ; p=0.005$, paired test).

\section{Inhibition may modulate TCC neurons in control and in $\mathrm{CCl}-\mathrm{loN}$ animals}

Vibrissal and GON stimulation induced excitatory responses in TCC neurons, which are in turn controlled by local inhibitory interneurons, which express GABA, Glycine, or both transmitters simultaneously (Fig. 6A; $[39,44])$.

\section{Effects of $G A B A_{A}$ receptor blockade}

Contrary to expectations, Bic application did not show a significant change in the spontaneous activity in 11 of the 13 neurons in control animals (from $0.6 \pm 0.46$ spikes/s in basal condition to $0.2 \pm 0.19$ spikes/s after Bic; $n=13 ; p=0.75$, paired test), nor in CCI-IoN cases (from $3.7 \pm 1.49$ to $3.42 \pm 1.19 ; n=15$; $p=0.96$ ). Moreover, the vibrissal responses decreased in 5 of the 13 neurons, increased in 7 neurons and in 1 they remained unchanged, resulting in a non-significant $34.4 \pm 30.1 \%$ increase after Bic $(n=13 ; p>0.9$, paired test; Fig. $6 \mathrm{~B})$. GON-responses decreased in the majority of neurons $(7$ out of 8) after Bic (by $49.62 \pm 13.6 \% ; n=8 ; p=0.023$, paired test) in controls. In the CCI-IoN cases, Bic had little effect on the responses to vibrissal stimulation: they decreased in 9 of the 15 neurons, increased in 4 neurons and remained unchanged in 2 neurons, resulting in a non-significant $4.13 \pm 13.3 \%$ decrease in the whole population ( $n=15 ; p=0.56$, paired test; Fig. $6 \mathrm{~B})$. As in the control cases, GON-responses were also significantly 

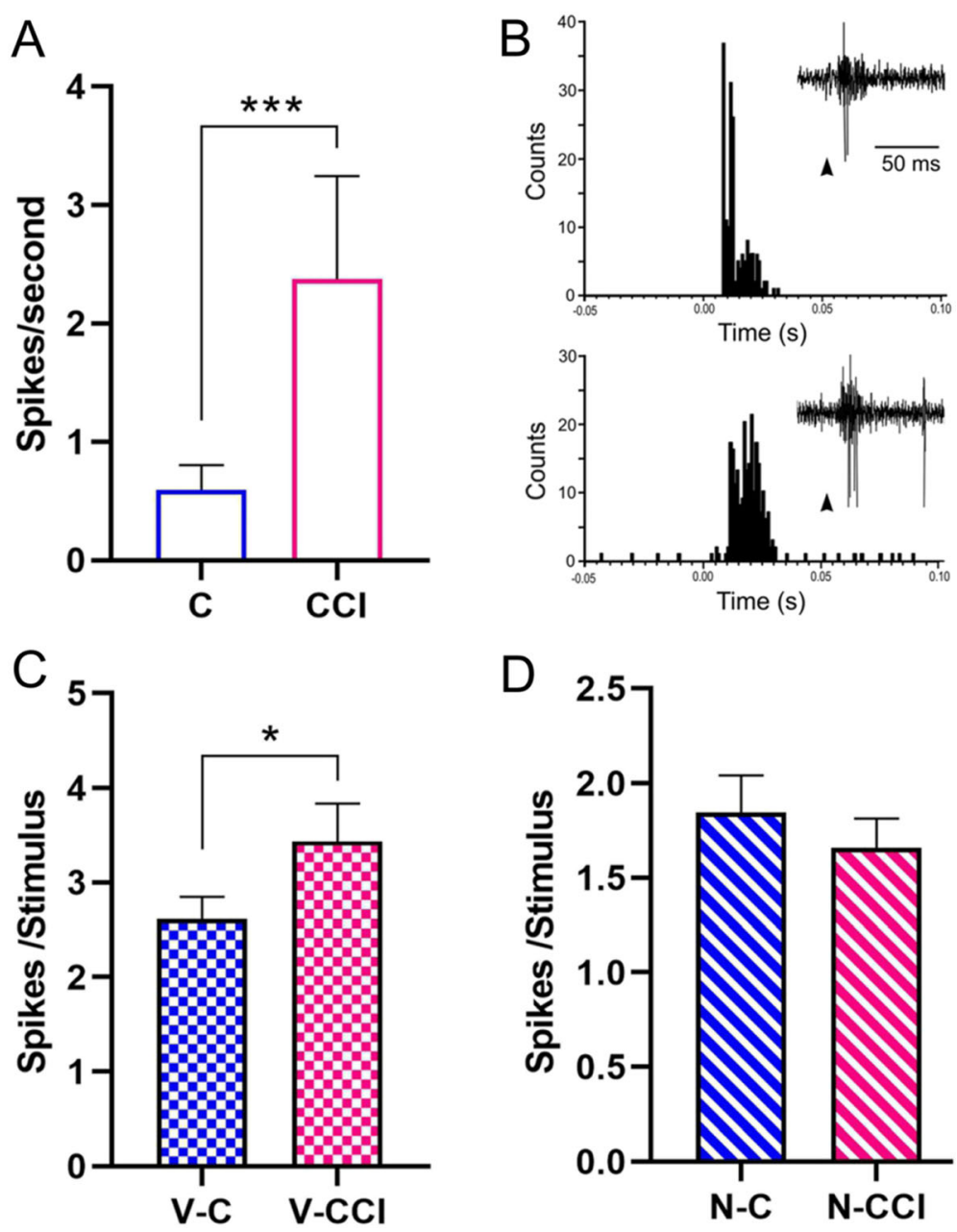

Fig. 3 Changes in spontaneous and input-evoked activity of TCC neurons after CCI-loN. (a) Frequency of spontaneous discharges increased fourfold in CCl-loN animals (C, control group; CCl, CCl-loN group). (b) Representative PSTHs of vibrissal responses (50 stimuli) in a control case (upper plot) and in a CCl-loN rat (lower plot). Insets show raw data examples; arrowheads indicate stimulus onset. The response was higher in the CCIIoN rat. (c) Plot of the mean vibrissal response in control and in CCI-loN animals. The response was greater in CCI-loN animals. (d) The response to GON stimulation did not differ significantly between control and CCI-IoN animals. V-C, vibrissal response in control animals; $\mathrm{V}-\mathrm{CCl}$, vibrissal response in $\mathrm{CCl}-\mathrm{loN}$ animals; $\mathrm{N}-\mathrm{C}, \mathrm{GON}$ response in control animals; $\mathrm{N}-\mathrm{CCl}, \mathrm{GON}$ response in $\mathrm{CCl}-\mathrm{IoN}$ animals; ${ }^{*} p<0.05 ;{ }^{* * *} p<0.0001$

reduced by Bic in the CCI-IoN animals: all the neurons tested showed a decrease, which reached on average $39.14 \pm 7.8 \%$ ( $n=7 ; p=0.015$, paired test). GON stimulation inhibited vibrissal responses in the presence of Bic (by $14.3 \pm 11.2 \% ; n=13 ; p=0.008$, paired test). Conversely, in the CCI-IoN animals, GON stimulation induced a facilitation of the vibrissal response after Bic application (by $18.6 \pm 2.7 \% ; n=15 ; p<0.0001$, paired test).

\section{Effects of Glycine receptor blockade}

Str application increased spontaneous firing in 9 of the 10 TCC neurons in controls (from $0.1 \pm 0.09$ spikes/s in basal condition to $1.0 \pm 0.51 \mathrm{spikes} / \mathrm{s}$ after Str application; $n=10 ; p=0.008$, paired test), and -although not significantly- in 6 of the 12 neurons in CCI-IoN cases (from $0.7 \pm 0.24$ spikes/s in basal condition to $1.7 \pm 0.53$ spikes/s under Str; $n=12 ; p=0.080$, paired test). Responses to vibrissal stimulation varied considerably in the TCC, with 4 of the 10 neurons increasing their response, 4 decreasing and 2 remaining unchanged (resulting in a non-significant $57.1 \pm 50.3 \%$ mean increase; $n=$ 10; $p=0.65$, paired test; Fig. $6 \mathrm{C}$ ). In contrast to Bic, Str increased GON-responses in all the neurons tested (by $30.2 \pm 12.5 \% ; n=7 ; p=0.031$, paired test). In the CCIIoN animals, Str also resulted in a variable response pattern to vibrissal stimulation: 6 of the 12 neurons increased their response, 5 decreased their response and in one of the neurons no effect was observed. This apparently large increase in responsivity (by $89.1 \pm 50 \%$ ) failed to reach statistical significance $(n=12 ; p=0.73$, paired test). GON-responses in the CCI-IoN animals showed a 


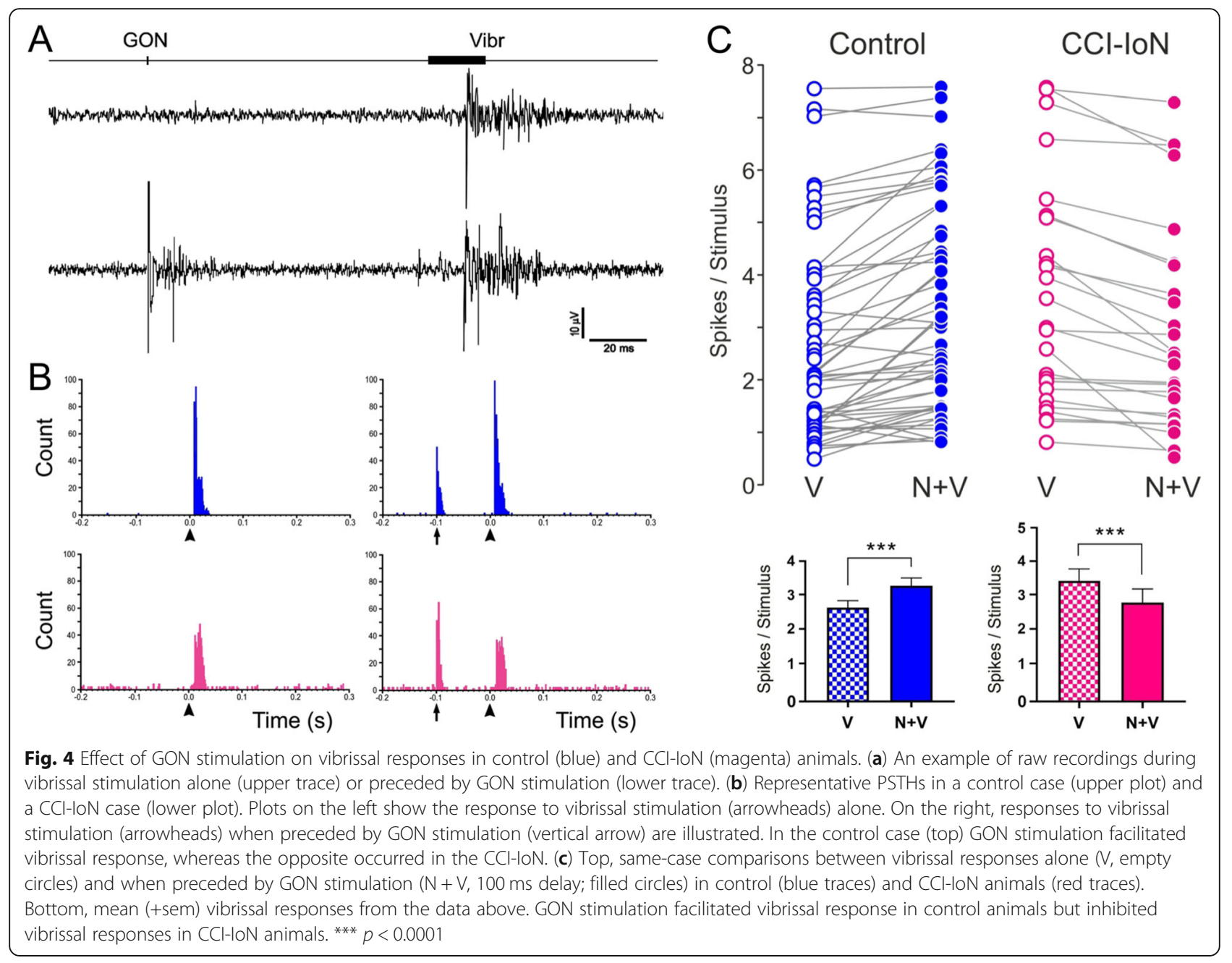

non-significant decrease in response in 6 of the 7 neurons (by $15.57 \pm 21.9 \% ; n=7 p=0.43$, paired test; Fig. $6 \mathrm{C}$ ). After Str application, GON stimulation inhibited vibrissal responses (by $18.6 \pm 5.3 \% ; n=10 ; p=0.008$, paired test). By contrast, in the CCI-IoN animals, GON stimulation induced a facilitation of the vibrissal response after Str application (by $31.3 \pm 11.13 \% ; n=12 ; p<0.001$, paired test).

\section{Effects of combined $G A B A_{A}$ and Glycine receptor blockade}

The application of a 'cocktail' containing Bic and Str (Fig. 6D) increased GON-responses in all cells tested (by $66.8 \pm 20.03 \% ; n=5 ; p=0.03$, paired test). In concurrence with above results, the application of the 'cocktail' did not significantly affect the vibrissal responses in the control TCC neuronal population, which slightly increased in 8 of the 12 neurons (by $17.9 \pm 13.4 \% ; n=12$; $p=0.42$, paired test). This treatment in the CCI-IoN animals, however, induced a significant increase of vibrissal response in the neuronal population (by $139.5 \pm 33.5 \%$; $n=10 ; p=0.002$, paired test), as well as of their responses to GON stimulation (by $127.1 \pm 45.3 \%$; $n=5 p=$
0.03, paired test). Compared with the effects of separate Bic or Str applications, when both blockers were applied GON stimulation exerted the opposite effects on the vibrissal response in all the TCC neurons. In the controls, the response increased by $38.1 \pm 6.04 \%(n=12 ; p<$ 0.001 , paired test), whereas in the CCI-IoN animals their responses decreased by $24.16 \pm 4.4 \% \quad(n=10 ; p=0.002$, paired test).

\section{Discussion}

The present results confirm and extend previous evidence of a convergence of trigeminal and GON afferents in the TCC (reviewed in [26]), and show that GON stimulation exerts different modulatory effects on trigeminal input in the TCC of intact animals and in animals that display pain and allodynia induced by the CCI of the IoN. When paired at intervals $<300 \mathrm{~ms}, \mathrm{GON}$ stimulation facilitates, in the TCC, neuronal responses to subsequent innocuous tactile stimuli to the vibrissal pad in control cases, whereas the same stimulation evokes an inhibition of vibrissal responses in CCI-IoN 


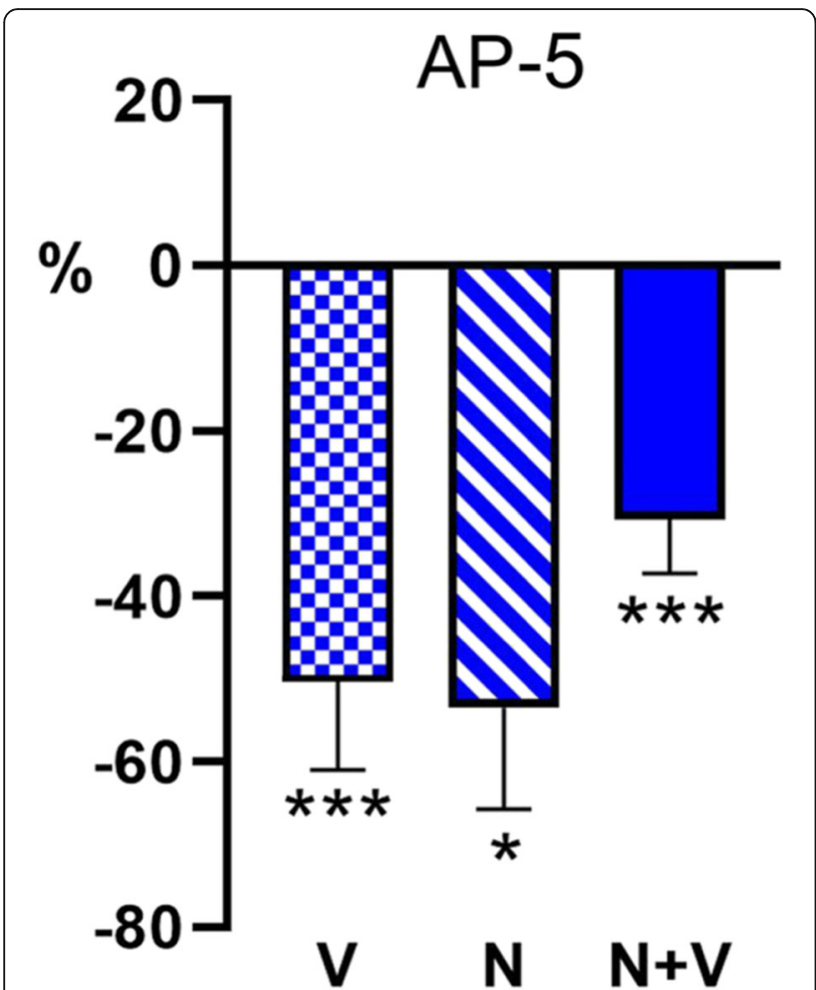

Fig. 5 Blocking of NMDA receptors by AP-5 caused a significant decrease in TCC neuronal responses. Vibrissal $(V)$ and GON (N) responses were halved by AP-5 $(50 \mu \mathrm{M})$. In addition, the GONevoked facilitation was blocked by AP- 5 and unmasked a GONevoked inhibition. * $p<0.05$; ${ }^{* *} p<0.0001$. All values are expressed as percentages with respect to the corresponding basal responses before AP-5 application

animals, an effect that is mediated by GABAergic and Glycinergic mechanisms. Vibrissal and GON stimulation-evoked spike firing of TCC neurons involve NMDA glutamatergic receptor activation, since it was reduced by the application of a NMDA-receptor antagonist, as also shown for responses to occipital muscle input in the TCC [33]. These findings may help to explain the beneficial effects of GON stimulation in treating some refractory craniofacial pain syndromes that involve trigeminal territories $[16,47,48]$.

\section{Primary afferents putatively driving the responses observed in TCC}

Impulses elicited by mild mechanical stimuli applied to the whisker pad are likely to emerge from all the mystacial, non-mystacial and intervibrissal fur low-threshold mechanoreceptors (LTMR) innervated by thickly- (A $\beta)$ and thinly-myelinated (A $\delta$ ) fibers [49-52]. In the spinal cord, $A \beta$ fibers distribute mainly in lamina III, with terminal and en passant boutons. Most boutons form the central component of type IIb glomeruli [53]), receiving axo-axonic contacts from presynaptic axons that express both GABA and Glycine (55-75\%, depending on the type of afferent), GABA only (25-40\%), or only Glycine (0$10 \%)$, and being in turn presynaptic to dendrites, which only in a small fraction of cases express either or both of these inhibitory transmitters [54-57]. In deeper laminae afferent boutons from $\mathrm{A} \beta$ fibers are replaced by simpler boutons, many of which still display triadic contacts with presynaptic axons that simultaneously synapse on the afferent bouton and a postsynaptic dendrite $[56,57]$. A $\delta$ fibers ending in laminae IIi-III mainly arise from LTMR in hair follicles [58, 59]. A similar pattern of LTMR fibers was described in the caudal $\mathrm{Sp} 5 \mathrm{C}$ in the cat $[60,61]$. In the rat, large boutons in terminal arbors of myelinated, $A \beta$ fibers, occupy the same layers with a somatotopic pattern [62-64].

The shortest-latency responses to GON electrical stimuli clearly fall within the range of $A \beta$ afferents. Thick fibers with abundant large- and medium-sized terminal and en passant boutons are distributed in the lateral one-third of laminae IIi-IV of the upper cervical segments and, more sparsely, along the lateral twothirds of $\mathrm{Sp} 5 \mathrm{C}$ and other lower brain stem structures [27]. Moreover, while the GON stimulation parameters (single pulse, twice the short latency response threshold) are unlikely to recruit unmyelinated $\mathrm{C}$ afferents, longer latency responses appearing within the $100 \mathrm{~ms}$ interval that mediate the GON and vibrissal stimulations likely represent $\mathrm{A} \delta$ fiber activation. Fine myelinated fibers, including $A \delta$ and low conduction velocity $A \beta$ afferents [65] from spinal nerves, distribute mainly in laminae IIIo and V [66], but may also reach intermediate laminae [67]. Myelinated afferents from GON in laminae II and IV form dense meshworks with terminal and en passant boutons of assorted sizes, while those in lamina I mainly consist of long thin axons decorated with abundant en passant varicosities, most of them small [27]. In deep laminae, boutons from finely myelinated fibers often make the central element of Type IIa glomeruli, which are postsynaptic to axonal boutons expressing GABA and/or Glycine, as well as GABA-expressing dendrites $[53,54]$. In laminae I-IIo these fibers establish simpler axo-dendritic synapses or make the central element of Type I glomeruli, which receive only GABAergic axoaxonic contacts $[53,54]$.

\section{TCC neurons driven by vibrissal and/or GON input}

All neurons in laminae I-VI had ipsilateral orofacial mechanoreceptive fields, with a predominance of those responding to low-threshold tactile input in laminae IIIIV [68]. Laminae IIi-IV of the spino-medullary dorsal horn, where most recordings were made, are the main target for LTMR afferents and a key node for early processing of tactile input. In these laminae in the spinal cord up to seven types of excitatory and four types of 

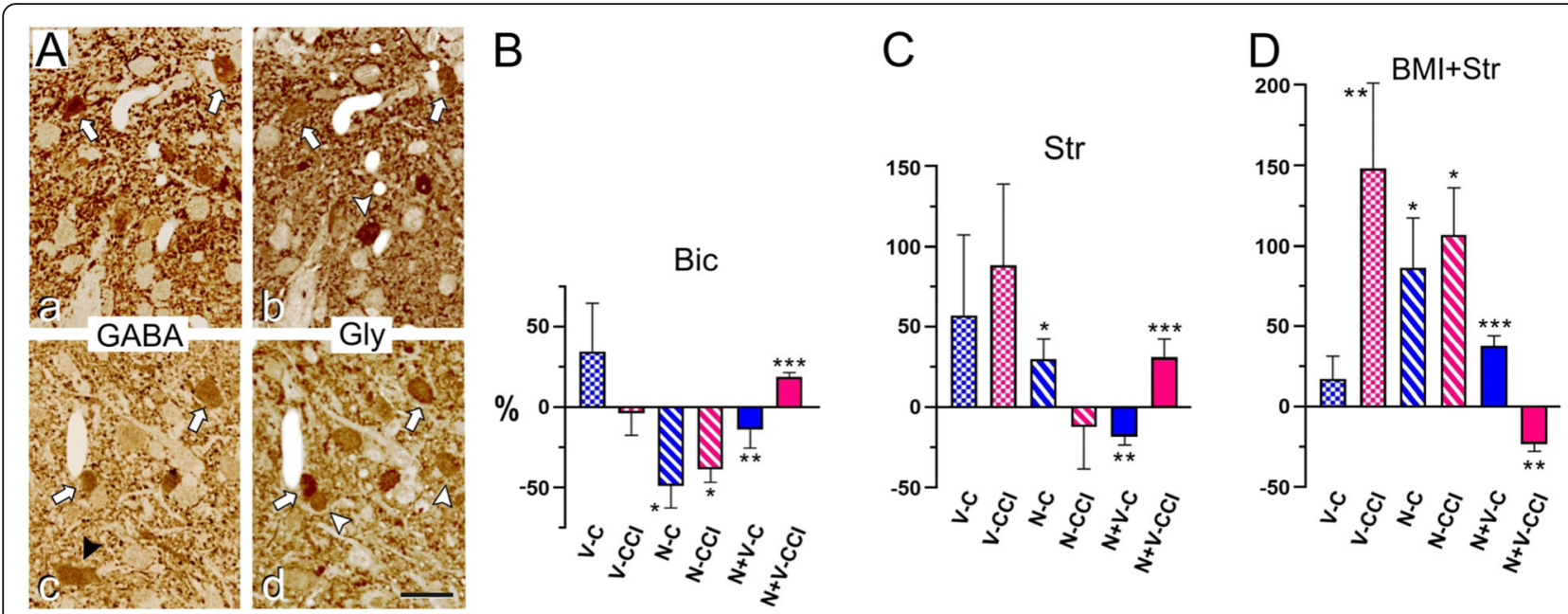

Fig. 6 (A) Examples of two pairs of GABA- $(\mathbf{a}, \mathbf{c})$ and Glycine-immunoreacted (b, d) consecutive semithin sections from laminae I-II (a, b) and III (c,d) at rostral levels of the TCC in a control rat. In agreement with previous findings (Avendaño et al., 2005), over one-third of neuron profiles display immunoreactivity for either GABA or Glycine. The majority shows various degrees of coexpression (some are indicated by white arrows), followed by those expressing only Glycine (white arrowheads). A small number of cells are only GABA-immunolabeled (black arrowhead in c). Scale bar $=20 \mu \mathrm{m}$. (B-D) Effect of antagonists of GABA- and Glycinergic neurotransmission on TCC neuronal responses. (B) In presence of the $\mathrm{GABA}_{\mathrm{A}}$ receptor antagonist bicuculline (Bic; $\left.20 \mathrm{mM}\right), \mathrm{GON}$ responses were reduced both in controls and CCl-loN cases, whereas vibrissal responses were essentially unaltered. (C) By contrast, the Glycinergic receptor antagonist strychnine (Str; $100 \mu \mathrm{M}$ ) increased, albeit non-significantly, the vibrissal responses in both groups, and significantly increased GON responses in controls. (D) When both antagonists were applied simultaneously (i.e. the 'cocktail' application; Bic, $20 \mathrm{mM}+\mathrm{Str}, 100 \mu \mathrm{M}$ ) there was a general increase of responses to vibrissae and GON stimulation, which only failed to reach significance for vibrissal responses in controls. The interaction of GON and vibrissal stimulation was affected in all cases by Bic, Str, or the 'cocktail' application, in the same directions if any of the drugs had been applied separately (reduced response to vibrissae in controls, and enhanced in CCl-loN cases), and in opposite directions when both drugs were applied simultaneously. Abbreviations as in Figs. 3 and 4 . All values are expressed as a percentage of change with respect to the corresponding basal responses before each drug application. ${ }^{*}, p<0.05 ;{ }^{* *}, p<0.01$; ***, $p<0.001$

inhibitory LTMR interneurons have been described on the basis of molecular-genetic, morphological and electrophysiological profiling [69-72]. These cells account for $98 \%$ of all neurons in the region, with a 2.3 -to- 1 ratio between excitatory and inhibitory cells, and just $2 \%$ of 'projection' neurons, which send their axons to supraspinal levels through the dorsal or lateral columns [71]. Most, if not all can be monosynaptically driven by primary afferent input to these laminae. Both nociceptive and non-nociceptive input from $A \delta$ afferents reach at least some excitatory (such as $\mathrm{PKC} Y$ neurons) and inhibitory (such as islet cells) neurons placed in lamina II and superficial part of III, as well as deeply-placed projection neurons with dendrites extending to superficial laminae [73]. The latter may also show convergence of all kinds of low- and high-threshold afferents [74]. Although comparably less thoroughly investigated, the corresponding laminae in the medullary dorsal horn contain similar neuronal populations and afferent input [75-77].

Although we cannot be sure of the cell type from which we obtained the recordings, indirect data may shed some light on this issue. Spontaneous firing is very low in both WDR and low-threshold mechanosensoryresponsive (LTM) neurons of $\mathrm{Sp5C}$ under control conditions; following CCI-IoN, however, spontaneous activity markedly increased in the WDR, but not in the LTM [39]. Moreover, it was recently found that excitatory neurons in laminae I-II in rat lumbar spinal cord showed fast adaptation to light tactile stimuli and very low spontaneous firing, whereas inhibitory neurons with a variety of non-adapting responses had much higher spontaneous activity ([78]; see also [38]). Should these findings be applicable to the neurons recorded in TCC, it would indicate that these neurons are likely to be excitatory interneurons or projection neurons.

\section{Responses in TCC to GON and vibrissal stimulation are differentially affected by $\mathrm{CCl}-\mathrm{loN}$}

Injured peripheral nerves exhibit increased ectopic firing, originating in the nerve itself [79] and/or medium-sized neurons in the $A \beta$ and $A \delta$ range in the affected spinal ganglia [80-82]. Both low- and high-threshold mechanosensory ganglion neurons become hyperexcitable and exhibit increased activity as attested by changes in several electrophysiological parameters, and thus may transfer as nociceptive messages normally innocuous tactile stimuli [83]. This abnormal input is responsible for all or most of the increased level of spontaneous activity in dorsal horn WDR neurons, because the conduction 
block of a constricted nerve proximal to the constriction abolishes it [79]. Nevertheless, the injured nerve causes additional effects, not only bringing about an altered drive on dorsal horn neurons. The sensory neurons affected by nerve lesions also undergo rapid and profound transcription changes [84, 85], so that large afferents change their expression of many transmitters, peptides, and other factors which contribute to drive sensitization and nociceptive responses in DH neurons (reviewed in [86]).

In addition to increased spontaneous activity, we found that the response in TCC to light tactile stimulation of the vibrissal pad increased significantly under CCI-IoN, as previously reported for somewhat more rostral levels of Sp5C [39]. A similar finding had also been reported in the lumbar spinal cord after sciatic CCI or spinal nerve ligation [38, 87]. While this increased response could be attributed to both an excess of incoming signals through the $\mathrm{IoN}$ and to hyperresponsive neurons in the TCC, it must be noted that such heightened response to peripheral stimuli was not found upon
GON stimulation (Fig. 7a). When a spinal nerve is injured, there is an increased expression of peptides involved in central sensitization in small and medium-sized DRG neurons contributing to a neighboring spared spinal nerve [88], as well as electrophysiological features of sensitization in $A \beta$, $A \delta$ and $C$ nociceptors [52]. These uninjured neurons show a notable overlap of thin afferents in the superficial laminae of the dorsal horn. However, while the GON and trigeminal terminals also show a degree of overlap in the TCC, the corresponding ganglia and peripheral course of these nerves are quite apart and GON ganglia and nerve are undamaged. The fact that responses to GON stimulation did not vary between the controls and CCI-IoN cases suggests that neurons in a TCC sensitized territory only appear hyperresponsive when driven from an injured ( $\mathrm{IoN}$ ) nerve, but not when activated from a converging, but intact (GON) nerve (Fig. 7a). Remarkably, this apparently unchanged response to GON stimulation was ensued by different effects on succeeding responses to facial tactile stimuli depending on whether IoN is, or is not injured, as discussed below.

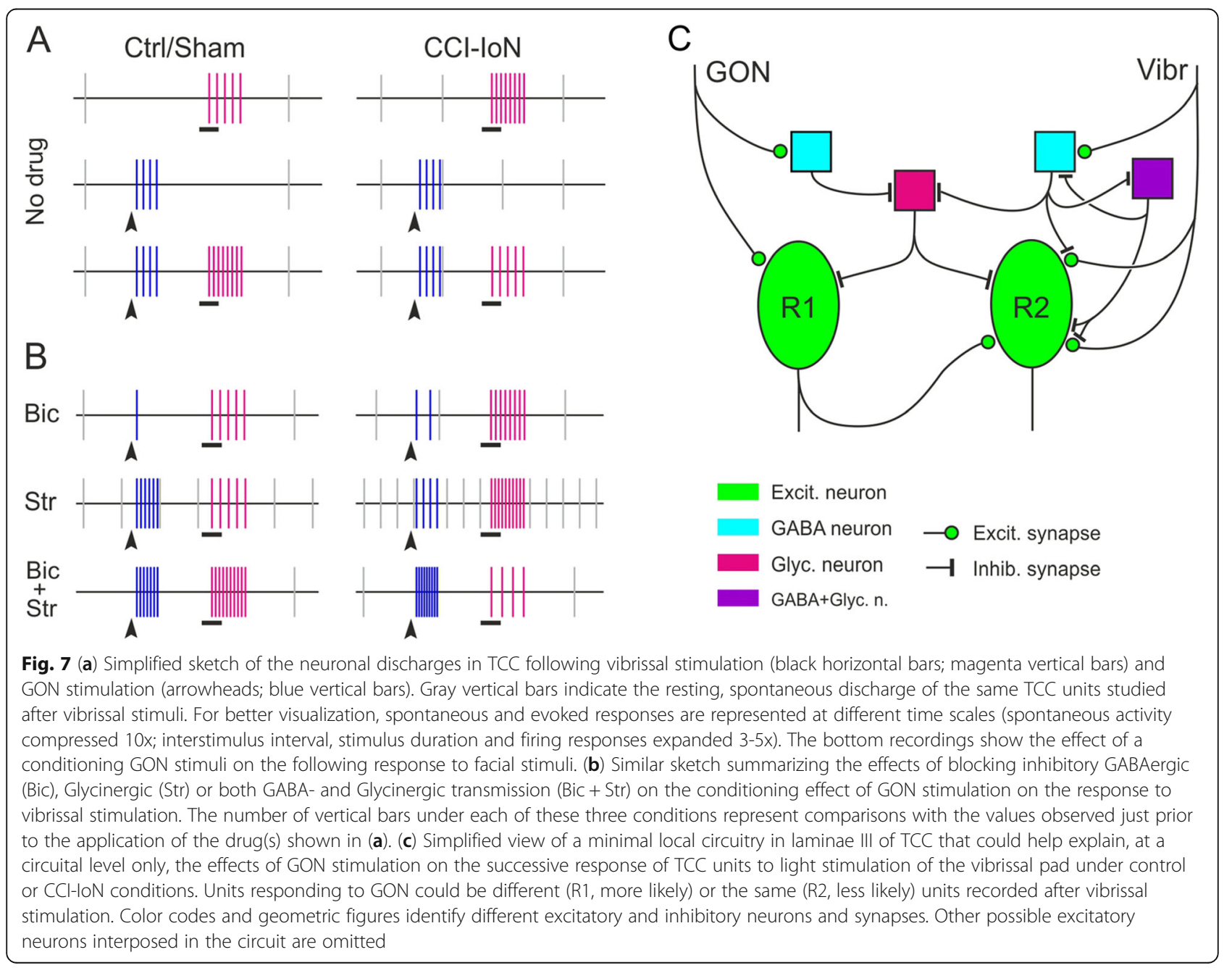


A conditioning stimulus to GON increases the TCC response to vibrissal stimulation in controls, but reduces it in CCl-loN cases

Despite the expanding use of GON stimulation to treat a variety of craniofacial pain disorders (reviewed in $[89,90]$ ), scarce attention has been paid to the basic neural mechanisms that may underlie this connection. Early electrophysiological and anatomical findings, mostly in cats, showed a convergence of GON and trigeminal afferents on upper cervical or medullary dorsal horn (see [27]). More recently, the existence was proved of a functional convergence in $\mathrm{Sp} 5 \mathrm{C}$ of nociceptive and non-nociceptive input from different trigeminal domains, such as the supratentorial dura mater and superficial territories of the first and second trigeminal branches [91]), as well as of a direct functional coupling in TCC neurons of dural and cervical afferents conveyed by the GON $[26,28]$. However, the interaction between low-threshold afferents and the GON input to TCC, under control and neuropathic conditions, still remained unexplored.

In controls, light vibrissal stimulation elicited a stronger response in the TCC when preceded by a brief electric shock to the GON. This facilitatory effect was due to the activation of NMDA receptors since the effect was blocked by AP-5. Since we could only ascertain that it was the same unit that responded to vibrissal and GON stimulation in some cases, the possibility exists that the GON effects on vibrissal responses are mediated by mono- or polysynaptic connections in the TCC. Those neurons receiving synapses from different sources may show heterosynaptic facilitation, whereby activation of some synapses on a target neuron may potentiate other inactive synapses on the same neuron. This has been demonstrated for low frequency stimulation of $\mathrm{C}$ and $\mathrm{A} \delta$ fibers in a dorsal root enhancing responses in a motor neuron to input from an adjacent intact root [92], for $\mathrm{C}$ fiber stimulation by topical mustard oil unmasking (potentiating) low-threshold A fiber input onto nociceptive-specific and wide dynamic range neurons at superficial or deep dorsal horn laminae [93], or for $\mathrm{C}$ or $\mathrm{A} \delta$ stimulation-mediated presynaptic potentiation of GABAergic synapses on lamina I neurons [94]. In absence of any direct proof, we think it unlikely that $A \delta$ (or $A \beta$ ) input on TCC neurons could potentiate the response to the vibrissal input in the same neurons by a similar mechanism. Moreover, the GON responses in the TCC were all but eliminated by blocking GABA transmission, and enhanced by blocking Glycine transmission (Fig. 7b), suggesting a release of an interposed Glycinergic inhibition probably through a GABAergic neuron, and therefore indicating a predominance of a multisynaptic enhancing effect of the GON activation on the vibrissal responses.

In the CCI-IoN cases, GON stimulation reduced the response to vibrissal stimulation to a level comparable to that seen in the control cases without prior GON stimulation (Fig. 7a). This decrease occurred within a significant increment in the spontaneous activity of the same TCC neurons, consistent with the overall state of GABA- and Glycine-dependent disinhibition in the affected spinal or medullary territory after a neuropathic injury ([39, 95]; see below). Given the essentially unchanged TCC response to GON stimulation compared to controls, it is therefore likely that input from the GON was able to 'rescue' local inhibitory circuits that were down-regulated by the nerve injury, thus reducing the TCC response to incoming vibrissal input. To summarize, under CCI, vibrissa-responding TCC units display heightened excitability revealed by their increased basal spontaneous discharges. Hence, GON conditioning is unlikely to affect directly the excitability level of TCC neurons but rather seems to temporally disinhibit local inhibitory GABAergic neurons, thus resetting presynaptic GABAergic and postsynaptic Glycinergic inhibition to normal levels.

\section{Inhibitory transmission in the TCC and its involvement in the effects of GON stimulation on vibrissal responses}

Inhibitory interneurons account for $30-40 \%$ of the neurons in laminae I-III of the rat spinal cord, most of which are enriched in GABA, fewer in Glycine, and an undetermined fraction expressing both transmitters in different combinations with other transmitters and neuropeptides [96-98]. In Sp5C about 33\% of the neurons express GABA and/or Glycine; of these immunolabeled neurons up to $52 \%$ co-express GABA and Glycine, and $17 \%$ and $32 \%$ express only GABA or only Glycine, respectively [44]. A population of the calcium-binding protein parvalbumin-expressing cells, morphologically assigned to the islet and central types in laminae IIi and dorsal III, co-express GABA and Glycine and have as their predominant synaptic output most of the axoaxonic synapses on boutons from $A \beta$ and $A \delta$ fibers within the same laminae $[99,100]$.

In addition to exerting presynaptic control on primary afferents, all the inhibitory interneurons make axodendritic and/or axosomatic contacts [71] and, through finely tuned mono- and polysynaptic effects, regulate the transmission of innocuous somatosensory input to other neurons that send both nociceptive and non-nociceptive signals to supraspinal levels (reviewed in $[69,101,102]$. In control conditions, these postsynaptic effects are aimed at controlling the excitability of the dorsal horn neurons, and blocking the flow of excitatory signals to nociceptive-specific projection neurons [103]. Dual simultaneous recordings of synaptically linked interneuron pairs in laminae III-IV have shown that inhibitory synapses outnumber the excitatory ones by $2: 1$ [104]. In these deeper laminae inhibitory interneurons expressing 
GAD67 receive predominantly Glycinergic synaptic contacts and are also under tonic extrasynaptic Glycinergic control, in contrast to similar interneurons in laminae IIIo, which are mostly targets for GABAergic synaptic and extrasynaptic modulation [105]. The importance of Glycinergic inhibition was also found in patch clamp studies on spinal slices, which showed that, although $55 \%$ of the neurons in lamina II receive GABA and Glycine synaptic input and all the neurons in laminae III-IV receive GABA and/or Glycinergic input, the inhibitory synaptic transmission is characterized in all cases by a dominant role of Glycinergic inhibition [106]. Moreover, GABA would be acting on presynaptic $\mathrm{GABA}_{\mathrm{B}}$ receptors, giving a negative feedback signal on the inhibitory afferent (reviewed in [107]). A similar GABA-mediated negative feedback has been shown to occur on glutamate release by $\mathrm{A} \beta$ terminals in laminae III-IV [108].

The separate or combined blockade of GABA or Glycine transmission revealed a complex involvement of inhibitory circuits in the effects of GON stimulation on vibrissal responses, and strongly suggests that the synaptic weight of GABAergic and Glycinergic inputs modulating GON and vibrissal inputs is not the same, under either control or CCI-IoN conditions. This complexity was compounded by the uncontrolled degree of penetration of the drugs, a variable in the design intended to mimic the effects of applying agonists or antagonists of inhibitory neurotransmitters intrathecally or intracisternally in both basic research [109-113] and clinical settings $[114,115]$. Yet, our findings may be supported by known local connections in the dorsal horn and provide new data on the possible involvement of these circuits under conditions of neuropathic pain.

The $\mathrm{GABA}_{\mathrm{A}}$ receptor blockade with Bic reduces the response to GON stimulation in both controls and CCIIoN cases, probably due to a disinhibition of Glycinergic neurons (see above). The effects on the vibrissal responses were negligible in both cases (Fig. 6), but these responses differed when preceded by GON stimulation: The facilitatory effect of GON pre-conditioning shown in controls disappears, consistent with the diminished response to GON stimulus; by contrast, under CCI-IoN, GON stimulation still facilitates the response to the successive facial stimulus, probably because of the local state of disinhibition caused by the CCI [39]. Glycinergic blockade, however, results in a quite different effect on the spontaneous activity, which increases in controls and even more under $\mathrm{CCI}$, and the response to GON, which also increases in controls, but is unaffected by CCI. This would be consistent with the dominant role of Glycinergic inhibition [106], whose removal would disinhibit units responding to the vibrissal input in controls, but would also disinhibit the down-regulated GABAergic transmission under CCI.
As expected, the combined removal of GABA- and Glycinergic transmission produces a marked increase in the responses to the GON and to the vibrissal inputs, but an intriguingly contrasting effect of the conditioning effect of GON stimulus on vibrissal input in controls and in CCI-IoN cases (Fig. 7b). In controls, a strong response to facial stimulation follows the strong response to GON stimulation, consistent with a global state of disinhibition. The heightened response to GON stimulation persists under CCI-IoN, but now the responses to vibrissal stimulation are somewhat decreased by a preceding GON stimulus. Although lacking experimental proof, it may be speculated that the strong response to GON input might have stimulated the release of GABA from local interneurons. With the $\mathrm{GABA}_{\mathrm{A}}$ receptors blocked by Bic, GABA could still activate $\mathrm{GABA}_{\mathrm{B}}$ receptors by the extrasynaptic diffusion of the transmitter, not just on a cell postsynaptic to the interneurons, but on other neurons as well [116]. These cells thus become less excitable by the activation of postsynaptic $\mathrm{GABA}_{\mathrm{B}}$ receptors [117], as will the vibrissal afferents themselves, since presynaptic $\mathrm{GABA}_{\mathrm{B}}$ receptors are expressed in terminals of $A \beta$ fibers in the spinal laminae III-IV [108]. The circuit diagram sketched in Fig. $7 \mathrm{c}$ gives grounds to the proposal that GON-driven alteration of the TCC responses to low-threshold input from the face can be explained, at least in part, by the interplay of inhibitory circuits that modulate the activation of presumed excitatory neurons.

\section{Conclusion}

GON stimulation exerts modulating and opposite effects on TCC neurons in CCI-IoN and control animals. Facilitation was NMDA-dependent while GABAergic and Glycinergic mechanisms mediated inhibition. This work will help us to advance the knowledge of the changes that occur in the synaptic circuitry in the TCC involved in chronic pain, as well as the mechanisms by which stimulating peripheral nerves may bring about beneficial effects on neuropathic pain. A deeper knowledge of these mechanisms will help to identify new therapeutic targets and improve treatments for a number of craniofacial painful conditions.

\footnotetext{
Abbreviations

AP-5: 2-amino-5-phosphonopentanoic acid; Bic: Bicuculline; CCl-loN: Chronic constriction injury of the rat infraorbital nerve; CTB: Fraction B of Cholera toxin; DAB: Diaminobenzidine; DC: Dorsal column; dps: Days post-surgery; DRG: Dorsal root ganglion; GABA: Gamma aminobutyric acid; GAD: Glutamic acid decarboxylase; GON: Greater occipital nerve; IB4: Isolectin IB4 from Griffonia simplicifolia; IoN: Infraorbital nerve; NMDA: N-methyl-D-aspartate; LTMR: Low-threshold mechanoreceptor(s); PKCY: Protein kinase C gamma; PSTH: Peristimulus time histogram; RF: Receptive field; Sp5C: Caudal division of the spinal trigeminal nucleus; Str: Strychnine; TCC: Trigeminocervical complex; TG: Trigeminal ganglion; WDR: Wide dynamic range
} 


\section{Acknowledgements}

The authors would like to thank Marta Callejo Móstoles and Gema de la Fuente Calvo for their technical support.

\section{Authors' contributions}

CA, PN, AN and NG-M designed the study. NG-M, YM, PN and AN performed the experiments. NG-M and AN were responsible for data acquisition and analysis of the results. CA and NG-M composed the Figures. CA, AN and NG$M$ wrote the manuscript. All authors read and commented on the final version of the manuscript and approved it to be published.

\section{Authors' information}

CA and AN are equally responsible as corresponding authors.

\section{Funding}

This research has been supported by Grant BFU2015-66941R from Spain's Ministerio de Economía Industria y Competitividad/Fondo Europeo de Desarrollo Regional (MINECO/FEDER) and SAF2016-76462 AEI/FEDER.

\section{Availability of data and materials}

The datasets generated for this study are available on request to the corresponding author.

\section{Ethics approval}

The animal study was reviewed and approved by the Ethical Committee of the Autonomous University of Madrid, in accordance with European Community's Council Directive 2010/63/UE with a permission number of 203/16.

\section{Consent for publication}

The authors approved the publication of this paper.

\section{Competing interests}

All authors declare that they have no competing interests.

\section{Author details}

'Department of Anatomy, Histology and Neuroscience, Medical School, Autonoma University of Madrid, c/ Arzobispo Morcillo 2, 28029 Madrid, Spain. ${ }^{2}$ Programme in Neuroscience, Doctoral School, Autonoma University of Madrid, Madrid, Spain. ${ }^{3}$ Facultad de Medicina, Universidad Francisco de Vitoria, 28223 Madrid, Spain.

\section{Received: 9 May 2020 Accepted: 17 July 2020}

Published online: 06 August 2020

\section{References}

1. Chakravarthy K, Nava A, Christo PJ, Williams K (2016) Review of recent advances in peripheral nerve stimulation (PNS). Curr Pain Headache Rep 20: 60. https://doi.org/10.1007/s11916-016-0590-8

2. Colini BG, Dario A, De CG, Luxardo N, Natale M, Nosella P et al (2017) Peripheral nerve stimulation in the treatment of chronic pain syndromes from nerve injury: a multicenter observational study. Neuromodulation 20: 369-374. https://doi.org/10.1111/ner.12539

3. Hofmeister M, Memedovich A, Brown S, Saini M, Dowsett LE, Lorenzetti DL et al (2019) Effectiveness of neurostimulation technologies for the management of chronic pain: a systematic review. Neuromodulation 23 : 150-157. https://doi.org/10.1111/ner.13020

4. Burns K, Bechara A (2007) Decision making and free will: a neuroscience perspective. Behav Sci Law 25:263-280. https://doi.org/10.1002/bsl.751

5. Bartsch T, Paemeleire K, Goadsby PJ (2009) Neurostimulation approaches to primary headache disorders. Curr Opin Neurol 22:262-268. https:/doi.org/ 10.1097/wco.0b013e32832ae61e

6. Magis D, Schoenen J (2012) Advances and challenges in neurostimulation for headaches. Lancet Neurol 11:708-719. https://doi.org/10.1016/S14744422(12)70139-4

7. Lambru G, Abu BN, Stahlhut L, McCulloch S, Miller S, Shanahan P et al (2014) Greater occipital nerve blocks in chronic cluster headache: a prospective open-label study. Eur J Neurol 21:338-343. https://doi.org/10. 1111/ene.12321
8. Puledda F, Goadsby PJ (2017) An update on non-pharmacological neuromodulation for the acute and preventive treatment of migraine. Headache 57:685-691. https://doi.org/10.1111/head.13069

9. Slavin KV, Nersesyan H, Wess C (2006) Peripheral neurostimulation for treatment of intractable occipital neuralgia. Neurosurgery 58:112-119. https://doi.org/10.1227/01.neu.0000192163.55428.62

10. Sweet JA, Mitchell LS, Narouze S, Sharan AD, Falowski SM, Schwalb JM et al (2015) Occipital nerve stimulation for the treatment of patients with medically refractory occipital neuralgia: congress of neurological surgeons systematic review and evidence-based guideline. Neurosurgery 77:332-341. https://doi.org/10.1227/NEU.0000000000000872

11. Keifer OP Jr, Diaz A, Campbell M, Bezchlibnyk YB, Boulis NM (2017) Occipital nerve stimulation for the treatment of refractory occipital neuralgia: a case series. World Neurosurg 105:599-604. https//doi.org/10.1016/j.wneu.2017.06.064

12. Saper JR, Dodick DW, Silberstein SD, McCarville S, Sun M, Goadsby PJ (2010) Occipital nerve stimulation for the treatment of intractable chronic migraine headache: ONSTIM feasibility study. Cephalalgia 31:271-285. https://doi.org/ 10.1177/0333102410381142

13. Dodick DW, Silberstein SD, Reed KL, Deer TR, Slavin KV, Huh B et al (2015) Safety and efficacy of peripheral nerve stimulation of the occipital nerves for the management of chronic migraine: long-term results from a randomized, multicenter, double-blinded, controlled study. Cephalalgia 35: 344-358. https://doi.org/10.1177/0333102414543331

14. Miller S, Watkins L, Matharu M (2016) Long-term outcomes of occipital nerve stimulation for chronic migraine: a cohort of 53 patients. J Headache Pain 17:68. https://doi.org/10.1186/s10194-016-0659-0

15. Rodrigo D, Acin P, Bermejo P (2017) Occipital nerve stimulation for refractory chronic migraine: results of a long-term prospective study. Pain Physician 20:E151-E159

16. Fontaine D, Bozzolo E, Chivoret N, Paquis P, Lanteri-Minet M (2014) Salvage treatment of trigeminal neuralgia by occipital nerve stimulation. Cephalalgia 34:307-310. https://doi.org/10.1177/0333102413508238

17. Arendt-Nielsen L (2015) Central sensitization in humans: assessment and pharmacology. Handb Exp Pharmacol 227:79-102. https://doi.org/10.1007/ 978-3-662-46450-2_5

18. Basbaum Al, Bautista DM, Scherrer G, Julius D (2009) Cellular and molecular mechanisms of pain. Cell 139:267-284. https://doi.org/10.1016/j.cell.2009.09. 028

19. Bartsch T, Goadsby PJ (2003) Increased responses in trigeminocervical nociceptive neurons to cervical input after stimulation of the dura mater. Brain 126:1801-1813. https://doi.org/10.1093/brain/awg190

20. Goadsby PJ, Holland PR, Martins-Oliveira M, Hoffmann J, Schankin C, Akerman S (2017) Pathophysiology of migraine: a disorder of sensory processing. Physiol Rev 97:553-622. https://doi.org/10.1152/physrev.00034. 2015

21. Goadsby PJ (2006) Primary neurovascular headache. In: McMahon SB, Koltzenburg M (eds) Wall and Melzack's textbook of pain, 5th edn. Philadelphia: Elsevier / Churchill Livingstone, pp 851-874

22. Kaube H, Katsarava Z, Przywara S, Drepper J, Ellrich J, Diener HC (2002) Acute migraine headache: possible sensitization of neurons in the spinal trigeminal nucleus? Neurology 58:1234-1238. https://doi.org/10.1212/wnl.58. 8.1234

23. Katsarava Z, Giffin N, Diener HC, Kaube H (2003) Abnormal habituation of 'nociceptive' blink reflex in migraine--evidence for increased excitability of trigeminal nociception. Cephalalgia 23:814-819. https://doi.org/10.1046/j. 1468-2982.2003.00591.x

24. Serrao M, Perrotta A, Bartolo M, Fiermonte G, Pauri F, Rossi P et al (2005) Enhanced trigemino-cervical-spinal reflex recovery cycle in pain-free migraineurs. Headache 45:1061-1068. https://doi.org/10.1111/j.1526-4610. 2005.05188.x

25. Coppola G, Di LC, Schoenen J, Pierelli F (2013) Habituation and sensitization in primary headaches. J Headache Pain 14:65. https://doi.org/10.1186/11292377-14-65

26. Goadsby PJ, Bartsch T (2010) The anatomy and physiology of the trigeminocervical complex. In: Fernández de las Peñas C, Arendt-Nielsen L, Gerwin RD (eds) Tension-type and cervicogenic headache: pathophysiology, diagnosis and treatment. Jones and Barlett, Sudbury, pp 109-116

27. García-Magro N, Martin YB, Negredo P, Avendano C (2018) The greater occipital nerve and its spinal and brainstem afferent projections: a stereological and tract-tracing study in the rat. J Comp Neurol 526:30003019. https://doi.org/10.1002/cne.24511 
28. Bartsch T, Goadsby PJ (2002) Stimulation of the greater occipital nerve induces increased central excitability of dural afferent input. Brain 125:14961509. https://doi.org/10.1093/brain/awf166

29. De La Cruz P, Gee L, Walling I, Morris B, Chen N, Kumar V et al (2015) Treatment of Allodynia by occipital nerve stimulation in chronic migraine rodent. Neurosurgery 77:479-485. https://doi.org/10.1227/NEU. 0000000000000846

30. Walling I, Smith H, Gee LE, Kaszuba B, Chockalingam A, Barborica A et al (2017) Occipital nerve stimulation attenuates neuronal firing response to mechanical stimuli in the ventral posteromedial thalamus of a rodent model of chronic migraine. Neurosurgery 81:696-701. https://doi.org/10. 1093/neuros/nyx135

31. Lyubashina OA, Panteleev SS, Sokolov AY (2017) Inhibitory effect of highfrequency greater occipital nerve electrical stimulation on trigeminovascular nociceptive processing in rats. J Neural Transm 124:171-183. https://doi.org/ 10.1007/s00702-016-1626-2

32. Classey JD, Knight YE, Goadsby PJ (2001) The NMDA receptor antagonist MK-801 reduces Fos-like immunoreactivity within the trigeminocervical complex following superior sagittal sinus stimulation in the cat. Brain Res 907:117-124. https://doi.org/10.1016/s0006-8993(01)02550-1

33. Le Doare K, Akerman S, Holland PR, Lasalandra MP, Bergerot A, Classey JD et al (2006) Occipital afferent activation of second order neurons in the trigeminocervical complex in rat. Neurosci Lett 403:73-77. https://doi.org/10. 1016/j.neulet.2006.04.049

34. Storer RJ, Goadsby PJ (1999) Trigeminovascular nociceptive transmission involves N-methyl-D-aspartate and non-N-methyl-D-aspartate glutamate receptors. Neuroscience 90:1371-1376. https://doi.org/10.1016/s03064522(98)00536-3

35. Hoffmann J, Storer RJ, Park JW, Goadsby PJ (2019) N-methyl-d-aspartate receptor open-channel blockers memantine and magnesium modulate nociceptive trigeminovascular neurotransmission in rats. Eur J Neurosci 50: 2847-2859. https://doi.org/10.1111/ejn.14423

36. Storer RJ, Akerman S, Goadsby PJ (2001) GABA receptors modulate trigeminovascular nociceptive neurotransmission in the trigeminocervical complex. Br J Pharmacol 134:896-904. https://doi.org/10.1038/sj.bjp.0704325

37. Moore KA, Kohno T, Karchewski LA, Scholz J, Baba H, Woolf CJ (2002) Partial peripheral nerve injury promotes a selective loss of GABAergic inhibition in the superficial dorsal horn of the spinal cord. J Neurosci 22:6724-6731 https://doi.org/20026611

38. Balasubramanyan S, Stemkowski PL, Stebbing MJ, Smith PA (2006) Sciatic chronic constriction injury produces cell-type-specific changes in the electrophysiological properties of rat substantia gelatinosa neurons. J Neurophysiol 96:579-590. https://doi.org/10.1152/jn.00087.2006

39. Martin YB, Malmierca E, Avendano C, Nunez A (2010) Neuronal disinhibition in the trigeminal nucleus caudalis in a model of chronic neuropathic pain. Eur J Neurosci 32:399-408. https://doi.org/10.1111/j. 1460-9568.2010.07302.x

40. Vos BP, Strassman AM, Maciewicz RJ (1994) Behavioral evidence of trigeminal neuropathic pain following chronic constriction injury to the rat's infraorbital nerve. J Neurosci 14:2708-2723

41. Bennett GJ, Xie YK (1988) A peripheral mononeuropathy in rat that produces disorders of pain sensation like those seen in man. Pain 33:87107. https://doi.org/10.1016/0304-3959(88)90209-6

42. Martin Y, Avendaño C, Piedras MJ, Krzyzanowska A (2010) Evaluation of Evans blue extravasation as a measure of peripheral inflammation. Nat Protoc Exch https://protocolexchange.researchsquare.com/article/nprot-1919/v1

43. Krzyzanowska A, Pittolo S, Cabrerizo M, Sanchez-Lopez J, Krishnasamy S, Venero C et al (2011) Assessing nociceptive sensitivity in mouse models of inflammatory and neuropathic trigeminal pain. J Neurosci Methods. https:// doi.org/10.1038/protex.2010.209

44. Avendaño C, Machin R, Bermejo PE, Lagares A (2005) Neuron numbers in the sensory trigeminal nuclei of the rat: a GABA- and glycineimmunocytochemical and stereological analysis. J Comp Neurol 493:538553. https://doi.org/10.1002/cne.20778

45. Matute C, Streit $P$ (1986) Monoclonal antibodies demonstrating GABA-like immunoreactivity. Histochemistry 86:147-157. https://doi.org/10.1007/ BF00493380

46. Haidarliu S, Ahissar E (1997) Spatial organization of facial vibrissae and cortical barrels in the Guinea pig and golden hamster. J Comp Neurol 385: 515-527. https://doi.org/10.1002/(sici)1096-9861(19970908)385:4\%3C515:.:aidcne3\%3E3.0.co;2-6
47. Miller S, Watkins L, Matharu M (2018) Long-term follow up of intractable chronic short lasting unilateral neuralgiform headache disorders treated with occipital nerve stimulation. Cephalalgia 38:933-942. https://doi.org/10. $1177 / 0333102417721716$

48. Wei DY, Jensen RH (2018) Therapeutic approaches for the management of trigeminal autonomic cephalalgias. Neurotherapeutics 15:346-360. https:// doi.org/10.1007/s13311-018-0618-3

49. Fundin BT, Arvidsson J, Aldskogius H, Johansson O, Rice SN, Rice FL (1997) Comprehensive immunofluorescence and lectin binding analysis of intervibrissal fur innervation in the mystacial pad of the rat. J Comp Neurol 385:185-206. https://doi.org/10.1002/(sici)1096-9861(19970825)385:2\%3C185: aid-cne2\%3E3.0.co;2-y

50. Abraira VE, Ginty DD (2013) The sensory neurons of touch. Neuron 79:618639. https://doi.org/10.1016/j.neuron.2013.07.051

51. Tonomura S, Ebara S, Bagdasarian K, Uta D, Ahissar E, Meir I et al (2015) Structure-function correlations of rat trigeminal primary neurons: emphasis on club-like endings, a vibrissal mechanoreceptor. Proc Jpn Acad Ser B Phys Biol Sci 91:560-576. https://doi.org/10.2183/pjab.91.560

52. Djouhri L (2016) Adelta-fiber low threshold mechanoreceptors innervating mammalian hairy skin: a review of their receptive, electrophysiological and cytochemical properties in relation to Adelta-fiber high threshold mechanoreceptors. Neurosci Biobehav Rev 61:225-238. https://doi.org/10. 1016/..neubiorev.2015.12.009

53. Ribeiro-da-Silva A (2004) The substantia gelatinosa of the rat spinal cord. In: Paxinos G (ed) The rat nervous system, 3rd edn. Academic, Sydney, pp 129-148

54. Todd AJ (1996) GABA and glycine in synaptic glomeruli of the rat spinal dorsal horn. Eur J Neurosci 8:2492-2498. https://doi.org/10.1111/j.1460-9568. 1996.tb01543.x

55. Watson AHD (2004) Synaptic interactions between the terminals of slowadapting type II mechanoreceptor afferents and neurones expressing gamma-aminobutyric acid- and glycine-like immunoreactivity in the rat spinal cord. J Comp Neurol 471:168-179. https://doi.org/10.1002/cne.20043

56. Watson AH (2003) GABA- and glycine-like immunoreactivity in axons and dendrites contacting the central terminals of rapidly adapting glabrous skin afferents in rat spinal cord. J Comp Neurol 464:497-510. https://doi.org/10. 1002/cne.10812

57. Watson AHD, Hughes DI, Bazzaz AA (2002) Synaptic relationships between hair follicle afferents and neurones expressing GABA and glycine-like immunoreactivity in the spinal cord of the rat. J Comp Neurol 452:367-380. https://doi.org/10.1002/cne.10410

58. Rethelyi M, Light AR, Perl ER (1982) Synaptic complexes formed by functionally defined primary afferent units with fine myelinated fibers. J Comp Neurol 207:381-393. https://doi.org/10.1002/cne.902070409

59. Olson W, Dong P, Fleming M, Luo W (2016) The specification and wiring of mammalian cutaneous low-threshold mechanoreceptors. Wiley Interdiscip Rev Dev Biol 5:389-404. https://doi.org/10.1002/wdev.229

60. Hayashi H (1985) Morphology of terminations of small and large myelinated trigeminal primary afferent fibers in the cat. J Comp Neurol 240:71-89. https://doi.org/10.1002/cne.902400106

61. Hayashi H (1985) Morphology of central terminations of intra-axonally stained, large, myelinated primary afferent fibers from facial skin in the rat. J Comp Neurol 237:195-215. https://doi.org/10.1002/cne.902370205

62. Jacquin MF, Renehan WE, Mooney RD, Rhoades RW (1986) Structurefunction relationships in rat medullary and cervical dorsal horns. I. Trigeminal primary afferents. J Neurophysiol 55:1153-1186. https://doi.org/ 10.1152/jn. 1986.55.6.1153

63. Jacquin MF, Mooney RD, Rhoades RW (1984) Axon arbors of functionally distinct whisker afferents are similar in medullary dorsal horn. Brain Res 298: 175-180. https://doi.org/10.1016/0006-8993(84)91165-x

64. Fernández-Montoya J, Martin YB, Negredo P, Avendano C (2018) Changes in the axon terminals of primary afferents from a single vibrissa in the rat trigeminal nuclei after active touch deprivation or exposure to an enriched environment. Brain Struct Funct 223:47-61. https://doi.org/10.1007/s00429017-1472-5

65. Djouhri L, Lawson SN (2004) Abeta-fiber nociceptive primary afferent neurons: a review of incidence and properties in relation to other afferent A-fiber neurons in mammals. Brain Res Brain Res Rev 46:131-145. https:// doi.org/10.1016/j.brainresrev.2004.07.015

66. Light AR, Perl ER (1979) Spinal termination of functionally identified primary afferent neurons with slowly conducting myelinated fibers. J Comp Neurol 186:133-150. https://doi.org/10.1002/cne.901860203 
67. Boada MD, Woodbury CJ (2008) Myelinated skin sensory neurons project extensively throughout adult mouse substantia gelatinosa. J Neurosci 28: 2006-2014. https://doi.org/10.1523/JNEUROSCI.5609-07.2008

68. Hu JW (1990) Response properties of nociceptive and non-nociceptive neurons in the rat's trigeminal subnucleus caudalis (medullary dorsal horn) related to cutaneous and deep craniofacial afferent stimulation and modulation by diffuse noxious inhibitory controls. Pain 41:331-345. https:// doi.org/10.1016/0304-3959(90)90010-b

69. Todd AJ (2010) Neuronal circuitry for pain processing in the dorsal horn. Nat Rev Neurosci 11:823-836. https://doi.org/10.1038/nrn2947

70. Tiong SY, Polgar E, van Kralingen JC, Watanabe M, Todd AJ (2011) Galaninimmunoreactivity identifies a distinct population of inhibitory interneurons in laminae I-III of the rat spinal cord. Mol Pain 7:36. https://doi.org/10.1186/ 1744-8069-7-36

71. Abraira VE, Kuehn ED, Chirila AM, Springel MW, Toliver AA, Zimmerman AL et al (2017) The cellular and synaptic architecture of the mechanosensory dorsal horn. Cell 168:295-310. https://doi.org/10.1016/j.cell.2016.12.010

72. Gutierrez-Mecinas M, Davis O, Polgar E, Shahzad M, Navarro-Batista K, Furuta T et al (2019) Expression of Calretinin among different neurochemical classes of interneuron in the superficial dorsal horn of the mouse spinal cord. Neuroscience 398:171-181. https://doi.org/10.1016/j.neuroscience. 2018.12 .009

73. Todd AJ (2015) Plasticity of inhibition in the spinal cord. Handb Exp Pharmacol 227:171-190. https://doi.org/10.1007/978-3-662-46450-2_9

74. Fernandes EC, Santos IC, Kokai E, Luz LL, Szucs P, Safronov BV (2018) Lowand high-threshold primary afferent inputs to spinal lamina III antenna-type neurons. Pain 159:2214-2222. https://doi.org/10.1097/j.pain. 0000000000001320

75. Gobel S (1975) Golgi studies in the substantia gelatinosa neurons in the spinal trigeminal nucleus. J Comp Neurol 162:397-415. https://doi.org/10. 1002/cne.901620308

76. Gobel S (1978) Golgi studies of the neurons in layer II of the dorsal horn of the medulla (trigeminal nucleus caudalis). J Comp Neurol 180:395-413. https://doi.org/10.1002/cne.901800213

77. Luz LL, Fernandes EC, Dora F, Lukoyanov NV, Szucs P, Safronov BV (2019) Trigeminal Adelta- and C-afferent supply of lamina I neurons in the trigeminocervical complex. Pain 160:2612-2623. https://doi.org/10.1097/j. pain.0000000000001659

78. Lee KY, Ratte S, Prescott SA (2019) Excitatory neurons are more disinhibited than inhibitory neurons by chloride dysregulation in the spinal dorsal horn. Elife:8. https://doi.org/10.7554/eLife.49753

79. Pitcher GM, Henry JL (2008) Governing role of primary afferent drive in increased excitation of spinal nociceptive neurons in a model of sciatic neuropathy. Exp Neurol 214:219-228. https://doi.org/10.1016/j.expneurol. 2008.08.003

80. Kajander KC, Wakisaka S, Bennett GJ (1992) Spontaneous discharge originates in the dorsal root ganglion at the onset of a painful peripheral neuropathy in the rat. Neurosci Lett 138:225-228. https://doi.org/10.1016/ 0304-3940(92)90920-3

81. Kajander KC, Bennett GJ (1992) Onset of a painful peripheral neuropathy in rat: a partial and differential deafferentation and spontaneous discharge in A beta and A delta primary afferent neurons. J Neurophysiol 68:734-744. https://doi.org/10.1152/jn.1992.68.3.734

82. Study RE, Kral MG (1996) Spontaneous action potential activity in isolated dorsal root ganglion neurons from rats with a painful neuropathy. Pain 65: 235-242. https://doi.org/10.1016/0304-3959(95)00216-2

83. Zhu YF, Henry JL (2012) Excitability of Abeta sensory neurons is altered in an animal model of peripheral neuropathy. BMC Neurosci 13:15. https://doi. org/10.1186/1471-2202-13-15

84. Xiao HS, Huang QH, Zhang FX, Bao L, Lu YJ, Guo C et al (2002) Identification of gene expression profile of dorsal root ganglion in the rat peripheral axotomy model of neuropathic pain. Proc Natl Acad Sci U S A 99:8360-8365. https://doi.org/10.1073/pnas.122231899

85. Lawson SN (2005) The peripheral sensory nervous system: dorsal root ganglion neurons. In: Dyck PJ, Thomas PK (eds) Peripheral neuropathy. W.B. Saunders; Elsevier Inc., New York, pp 163-202

86. Latremoliere A, Woolf CJ (2009) Central sensitization: a generator of pain hypersensitivity by central neural plasticity. J Pain 10:895-926. https://doi. org/10.1016/j.jpain.2009.06.012

87. Pertovaara A, Kontinen VK, Kalso EA (1997) Chronic spinal nerve ligation induces changes in response characteristics of nociceptive spinal dorsal horn neurons and in their descending regulation originating in the periaqueductal gray in the rat. Exp Neurol 147:428-436. https://doi.org/10. 1006/exnr.1997.6555

88. Fukuoka T, Noguchi K (2002) Contribution of the spared primary afferent neurons to the pathomechanisms of neuropathic pain. Mol Neurobiol 26: 57-67. https://doi.org/10.1385/MN:26:1:057

89. Antony AB, Mazzola AJ, Dhaliwal GS, Hunter CW (2019) Neurostimulation for the treatment of chronic head and facial pain: a literature review. Pain Physician 22:447-477

90. Slavin KV, Isagulyan ED, Gomez C, Yin D (2019) Occipital nerve stimulation. Neurosurg Clin N Am 30:211-217. https://doi.org/10.1016/j.nec.2018.12.004

91. Schepelmann K, Ebersberger A, Pawlak M, Oppmann M, Messlinger K (1999) Response properties of trigeminal brain stem neurons with input from dura mater encephali in the rat. Neuroscience 90:543-554. https://doi.org/10. 1016/s0306-4522(98)00423-0

92. Thompson SW, Woolf CJ, Sivilotti LG (1993) Small-caliber afferent inputs produce a heterosynaptic facilitation of the synaptic responses evoked by primary afferent A-fibers in the neonatal rat spinal cord in vitro. J Neurophysiol 69:2116-2128. https://doi.org/10.1152/jn.1993.69.6.2116

93. Woolf CJ, Shortland P, Sivilotti LG (1994) Sensitization of high mechanothreshold superficial dorsal horn and flexor motor neurones following chemosensitive primary afferent activation. Pain 58:141-155. https://doi.org/10.1016/0304-3959(94)90195-3

94. Fenselau H, Heinke B, Sandkuhler J (2011) Heterosynaptic long-term potentiation at GABAergic synapses of spinal lamina I neurons. J Neurosci 31:17383-17391. https://doi.org/10.1523/JNEUROSCI.3076-11.2011

95. Imlach WL, Bhola RF, Mohammadi SA, Christie MJ (2016) Glycinergic dysfunction in a subpopulation of dorsal horn interneurons in a rat model of neuropathic pain. Sci Rep 6:37104. https://doi.org/10.1038/ srep37104

96. Todd AJ, Sullivan AC (1990) Light microscope study of the coexistence of GABA-like and glycine-like immunoreactivities in the spinal cord of the rat. J Comp Neurol 296:496-505. https://doi.org/10.1002/cne.902960312

97. Todd AJ (1991) Immunohistochemical evidence that acetylcholine and glycine exist in different populations of GABAergic neurons in lamina III of rat spinal dorsal horn. Neuroscience 44:741-746. https://doi.org/10.1016/ 0306-4522(91)90093-4

98. Laing I, Todd AJ, Heizmann CW, Schmidt HHHW (1994) Subpopulations of GABAergic neurons in laminae I-III of rat spinal dorsal horn defined by coexistence with classical transmitters, peptides, nitric oxide synthase or parvalbumin. Neuroscience 61:123-132. https://doi.org/10.1016/03064522(94)90065-5

99. Hughes DI, Sikander S, Kinnon CM, Boyle KA, Watanabe M, Callister RJ et al (2012) Morphological, neurochemical and electrophysiological features of parvalbumin-expressing cells: a likely source of axo-axonic inputs in the mouse spinal dorsal horn. J Physiol 590:3927-3951. https://doi.org/10.1113/ jphysiol.2012.235655

100. Boyle KA, Gradwell MA, Yasaka T, Dickie AC, Polgar E, Ganley RP et al (2019) Defining a spinal microcircuit that gates myelinated afferent input: implications for tactile Allodynia. Cell Rep 28:526-540. https://doi.org/10. 1016/j.celrep.2019.06.040

101. Peirs C, Bourgois N, Artola A, Dallel R (2016) Protein kinase C gamma interneurons mediate C-fiber-induced orofacial secondary static mechanical Allodynia, but not C-fiber-induced nociceptive behavior. Anesthesiology 124:1136-1152. https://doi.org/10.1097/ALN.0000000000001000

102. Benarroch EE (2016) Dorsal horn circuitry: complexity and implications for mechanisms of neuropathic pain. Neurology 86:1060-1069. https://doi.org/ 10.1212/WNL.0000000000002478

103. Guo D, Hu J (2014) Spinal presynaptic inhibition in pain control. Neuroscience 283:95-106. https://doi.org/10.1016/j.neuroscience.2014.09.032

104. Schneider SP (2008) Local circuit connections between hamster laminae III and IV dorsal horn neurons. J Neurophysiol 99:1306-1318. https://doi.org/ 10.1152/jn.00962.2007

105. Takazawa T, MacDermott AB (2010) Glycinergic and GABAergic tonic inhibition fine tune inhibitory control in regionally distinct subpopulations of dorsal horn neurons. J Physiol 588:2571-2587. https://doi.org/10.1113/ jphysiol.2010.188292

106. Inquimbert $\mathrm{P}$, Rodeau JL, Schlichter R (2007) Differential contribution of GABAergic and glycinergic components to inhibitory synaptic transmission in lamina II and laminae III-IV of the young rat spinal cord. Eur J Neurosci 26:2940-2949. https://doi.org/10.1111/j.1460-9568.2007.05919.x 
107. Zeilhofer HU, Wildner H, Yevenes GE (2012) Fast synaptic inhibition in spinal sensory processing and pain control. Physiol Rev 92:193-235. https://doi. org/10.1152/physrev.00043.2010

108. Salio C, Merighi A, Bardoni R (2017) GABAB receptors-mediated tonic inhibition of glutamate release from Abeta fibers in rat laminae III/IV of the spinal cord dorsal horn. Mol Pain 13:1744806917710041. https://doi.org/10. 1177/1744806917710041

109. Yaksh TL (1989) Behavioral and autonomic correlates of the tactile evoked allodynia produced by spinal glycine inhibition: effects of modulatory receptor systems and excitatory amino acid antagonists. Pain 37:111-123. https://doi.org/10.1016/0304-3959(89)90160-7

110. Sivilotti L, Woolf CJ (1994) The contribution of GABAA and glycine receptors to central sensitization: disinhibition and touch-evoked allodynia in the spinal cord. J Neurophysiol 72:169-179. https://doi.org/10.1152/jn.1994.72.1.169

111. Ishikawa T, Marsala M, Sakabe T, Yaksh TL (2000) Characterization of spinal amino acid release and touch-evoked allodynia produced by spinal glycine or GABA(A) receptor antagonist. Neuroscience 95:781-786. https://doi.org/ 10.1016/50306-4522(99)00461-3

112. Lee IO, Whitehead RA, Ries CR, Schwarz SK, Puil E, MacLeod BA (2013) Evaluation of a novel mouse model of intracisternal strychnine-induced trigeminal allodynia. Can J Anaesth 60:780-786. https://doi.org/10.1007/ s12630-013-9975-

113. Meuwissen KPV, de Vries LE, Gu JW, Zhang TC, Joosten EAJ (2020) Burst and tonic spinal cord stimulation both activate spinal GABAergic mechanisms to attenuate pain in a rat model of chronic neuropathic pain. Pain Pract 20:7587. https://doi.org/10.1111/papr.12831

114. Munts AG, van der Plas AA, Voormolen JH, Marinus J, Teepe-Twiss IM, Onkenhout W et al (2009) Intrathecal glycine for pain and dystonia in complex regional pain syndrome. Pain 146:199-204. https://doi.org/10.1016/ j.pain.2009.07.030

115. Goslinga-van der Gaag S, Delhaas EM, Frankema SPG, Huygen FJPM (2019) Efficiency and safety of aftercare with intrathecal baclofen on location. Neuromodulation 22:828-833. https://doi.org/10.1111/ner.13038

116. Scanziani M (2000) GABA spillover activates postsynaptic GABA(B) receptors to control rhythmic hippocampal activity. Neuron 25:673-681. https://doi. org/10.1016/s0896-6273(00)81069-7

117. Malcangio M (2018) GABAB receptors and pain. Neuropharmacology 136: 102-105. https://doi.org/10.1016/j.neuropharm.2017.05.012

\section{Publisher's Note}

Springer Nature remains neutral with regard to jurisdictional claims in published maps and institutional affiliations.

Ready to submit your research? Choose BMC and benefit from:

- fast, convenient online submission

- thorough peer review by experienced researchers in your field

- rapid publication on acceptance

- support for research data, including large and complex data types

- gold Open Access which fosters wider collaboration and increased citations

- maximum visibility for your research: over $100 \mathrm{M}$ website views per year

At BMC, research is always in progress.

Learn more biomedcentral.com/submissions 